\title{
The Cross-Section of Stock Returns in Frontier Emerging Markets
}

\author{
Wilma de Groot Juan Pang Laurens Swinkels \\ 2012-08
}

\begin{abstract}
We are the first to investigate the cross-section of stock returns in the new emerging equity markets, the so-called frontier emerging markets. Our unique survivorship-bias free data set consists of more than 1,400 stocks over the period 1997 to 2008 and covers 24 of the most liquid frontier emerging markets. The major benefit of using individual stock characteristics is that it allows us to investigate whether return factors that have been documented in developed countries also exist in these markets. We document the presence of economically and statistically significant value and momentum effects, and a local size effect. Our results indicate that the value and momentum effects still exist when incorporating conservative assumptions of transaction costs. Additionally, we show that value, momentum, and local size returns in frontier markets cannot be explained by global risk factors.
\end{abstract}

Keywords: Alpha; Behavioral finance; Emerging markets; Frontier markets; Momentum effect; Size effect; Value effect

JEL codes: F21; F30; G11; G15 


\begin{tabular}{|c|c|}
\hline \multicolumn{2}{|c|}{ ERIM Report Series Research in Management } \\
\hline ERIM Report Series reference number & ERS-2012-012-F\&A \\
\hline Date of publication & $2012-08$ \\
\hline Version & August 2012 \\
\hline Number of pages & 58 \\
\hline Persistent URL for paper & http://hdl.handle.net/1765/37284 \\
\hline Email address corresponding author & lswinkels@ese.eur.nl \\
\hline Address & $\begin{array}{l}\text { Erasmus Research Institute of Management } \\
\text { (ERIM) } \\
\text { RSM Erasmus University / Erasmus School } \\
\text { of Economics } \\
\text { Erasmus University Rotterdam } \\
\text { PO Box } 1738 \\
3000 \text { DR Rotterdam, The Netherlands } \\
\text { Phone: +31104081182 } \\
\text { Fax: +31104089640 } \\
\text { Email: info@erim.eur.nl } \\
\text { Internet: http://www.erim.eur.nl }\end{array}$ \\
\hline Availability & 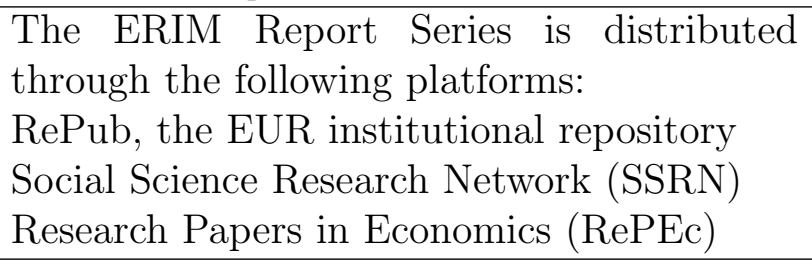 \\
\hline Classifications & $\begin{array}{l}\text { The electronic versions of the papers in the } \\
\text { ERIM Report Series contain bibliographic } \\
\text { metadata from the following classification } \\
\text { systems: } \\
\text { Library of Congress Classification (LCC) } \\
\text { Journal of Economic Literature (JEL) } \\
\text { ACM Computing Classification System } \\
\text { Inspec Classification Scheme (ICS) }\end{array}$ \\
\hline
\end{tabular}




\title{
The Cross-Section of Stock Returns
}

\author{
in

\section{Frontier Emerging Markets*}

\author{
Wilma de Groot \\ Robeco Quantitative Strategies \\ $\underline{\text { w.de.groot@ robeco.com }}$ \\ Juan Pang \\ Robeco Quantitative Strategies \\ j.pang@ robeco.com \\ Laurens Swinkels \\ Erasmus Research Institute of Management \\ Erasmus School of Economics \\ Robeco Quantitative Strategies \\ lswinkels@ese.eur.nl
}

August 2012

This research paper is available online at

http://ssrn.com/abstract $=1600023$

and

$\underline{\text { www.robeco.com/quant }}$

This paper is forthcoming in the Journal of Empirical Finance

\footnotetext{
* Laurens Swinkels is the corresponding author. We would like to thank Guido Baltussen, Jules van Binsbergen, David Blitz, Charles Calomiris, Ana Carmen Díaz-Mendoza, Leo de Haan, Jaap van der Hart, Campbell Harvey, Emre Konukoglu, Hao Jiang, Simon Lansdorp, Bill Miles, Lord Mensah, Marcel Moellenbeck, Pim van Vliet, seminar participants of Erasmus University Rotterdam (Netherlands), Groningen University (Netherlands), South Western University of Finance and Economics (Chengdu, China) and Maastricht University (Netherlands), and conference participants of the $18^{\text {th }}$ Spanish Finance Forum (Alicante, Spain), $3^{\text {rd }}$ Emerging Markets Group Conference (London, United Kingdom), $14^{\text {th }}$ Conference of the Swiss Society for Financial Markets Research (Zurich, Switzerland), the 2011 Eastern Finance Association Annual Meeting (Savannah, United States), and the $2^{\text {nd }}$ World Finance Forum (Rhodes, Greece) for valuable comments and Jornt Beetstra, Weili Zhou, and Liz Bond for excellent research and editorial assistance. The views expressed in this paper are not necessarily shared by Robeco or any of its subsidiaries.
} 


\title{
The Cross-Section of Stock Returns
}

\author{
in \\ Frontier Emerging Markets
}

\begin{abstract}
We are the first to investigate the cross-section of stock returns in the new emerging equity markets, the so-called frontier emerging markets. Our unique survivorship-bias free data set consists of more than 1,400 stocks over the period 1997 to 2008 and covers 24 of the most liquid frontier emerging markets. The major benefit of using individual stock characteristics is that it allows us to investigate whether return factors that have been documented in developed countries also exist in these markets. We document the presence of economically and statistically significant value and momentum effects, and a local size effect. Our results indicate that the value and momentum effects still exist when incorporating conservative assumptions of transaction costs. Additionally, we show that value, momentum, and local size returns in frontier markets cannot be explained by global risk factors.
\end{abstract}

Keywords: Alpha, Behavioral finance, Emerging markets, Frontier Markets, Momentum effect, Size effect, Value effect

JEL classification: F21, F30, G11, G15 


\section{Introduction}

Traditional emerging markets have developed rapidly over the past decades, both economically and financially. A group of countries less developed than emerging markets with established stock exchanges has appeared on the radar screen of global investors. These new emerging markets as a group are also known as frontier emerging markets, or in short, frontier markets. These countries vary greatly in their economic development. The GDP per capita in 2008 of Bangladesh, for example is just $\$ 497$ while that of Slovenia is $\$ 27,019 .^{2}$ The market capitalization of stocks in frontier emerging markets in October 2008 is $\$ 113.6$ billion. ${ }^{3}$ Although still smaller than traditional emerging and developed stock markets, these markets are becoming more important, as evidenced for example by recent listings of new mutual funds and exchange-traded funds on frontier markets. ${ }^{4}$ In addition, for academics, frontier emerging markets are an untapped data source that provides excellent out-of-sample research opportunities.

Investors who are interested in improving the risk-return trade-off of their portfolios could expand their investment opportunity set by including frontier equity markets. Goetzmann, Li, and Rouwenhorst (2005) indicate that investors should be willing to keep expanding their investment horizon to new equity markets to get a better diversified portfolio. Speidell and Krohne (2007) also mention diversification benefits as a key motivation for investors to include frontier markets in their investment portfolios. Berger, Pukthuanthong, and Yang (2011) investigate whether frontier equity markets are integrated with developed equity markets and conclude that this is not the case. These studies have in common that they consider frontier markets as a

\footnotetext{
${ }^{2}$ Data source: World Bank Development Indicators, available online at http://data.worldbank.org. For comparison the GDP per capita of some other countries: Brazil $\$ 8,205$, Russia $\$ 11,832$, India $\$ 1,019$, China $\$ 3,267$, Afghanistan $\$ 366$, Portugal $\$ 22,923$, and the United States $\$ 46,350$.

${ }^{3}$ This is the market capitalisation of the constituents of the Standard \& Poor's Frontier Broad Market Index. Actual market capitalisation is higher because of exchange listed stocks that are not in this index and adjustments made to exclude the market capitalization part of the company that is inaccessible to (foreign) investors.

${ }^{4}$ For example, the Harding Loevner Frontier Emerging Markets Institutional (ticker: HLFMX) fund was launched on 27 May 2008 (total assets 5/31/2012: \$68 mln), the Morgan Stanley Frontier Emerging Markets (ticker: FFD) fund was launched on 22 August 2008 (total assets 3/31/2012: \$78 mln), the Templeton Frontier Markets (ticker: TFMAX) fund was launched on 14 October 2008 (total assets 4/30/2011: $\$ 383 \mathrm{mln}$ ), the Forward Frontier Markets (ticker: FRNMX) fund was launched on 31 December 2008 (total assets 5/31/2012: \$70 mln) and the Guggenheim Frontier Markets (ticker: FRN) exchange-traded fund was launched on 12 June 2008 (total assets 4/30/2012: \$137mln). Sources: Morningstar and Yahoo Finance.
} 
group or consider them at the country level. However, little is known about the risk, return, and diversification characteristics of return factors based on individual stock data in frontier markets. ${ }^{5}$ Our unique survivorship-bias free data set on individual stock characteristics in frontier markets allows us to construct portfolios based on other characteristics than the country of stock exchange listing. Hence, we are able to investigate the existence of value, momentum, size, and low-risk effects in these markets over the period 1997 to 2008 and gauge how much stronger these effects are when employed at the stock rather than the country level. Moreover, our data enables us to investigate whether investment strategies based on these cross-sectional stock attributes are correlated between developed, emerging, and frontier markets. Our paper aims to fill these gaps in the literature.

This paper contributes to the literature on at least three dimensions. First, our results provide out-of-sample evidence for the existence of value, momentum, and local size effects. Sorting stocks in frontier markets on value characteristics, such as book-toprice ratios, momentum characteristics, such as past 6-month returns, or market capitalization per country yield statistically significant positive excess returns for the top quintile portfolios versus the index of $5 \%$ to $15 \%$ per annum. Our study extends the results by Fama and French (1998) and Rouwenhorst (1999) for international evidence on the value effect. Our results also reinforce the international evidence of the momentum effect reported by Griffin, Ji, and Martin (2003) and Rouwenhorst (1998, 1999). Our results are further empirical evidence that value and momentum are present everywhere, as suggested by Asness, Moskowitz, and Pedersen (2009). The presence of a local size effect confirms evidence in Europe by Heston, Rouwenhorst, and Wessels (1999) and emerging markets by Rouwenhorst (1999). Our results are important, as frontier markets are least integrated with developed and emerging equity markets, yet, the cross-section of stock returns seems to produce excess returns on exactly the same factors.

Second, we are the first to investigate the profitability of value and momentum effects in frontier markets in detail when faced with real life market imperfections. We incorporate transaction costs estimates of $2.5 \%$ per single-trip transaction from

\footnotetext{
${ }^{5}$ A notable exception is Girard and Sanha (2008), who use individual stock data of frontier markets to assess the importance of political risk in frontier market investments.
} 
Marshall, Nguyen, and Visaltanochoti (2011) covering bid-ask spreads, market impact and commissions. We deem this to be a conservative estimate as we consider the largest half of our sample and apply a one-month lag between ranking and portfolio formation to account for possible opportunity costs. Our empirical findings indicate that transaction costs have a large impact on the profitability of value and momentum strategies. However, we still observe economically and statistically significant returns of approximately $6.6 \%$ to $7.7 \%$ per annum after incorporating transactions costs for value strategies and net returns of $4.6 \%$ to $7.2 \%$ for momentum strategies. These findings seem to be inconsistent with market efficiency.

Third, we analyze whether exposure to global risk factors can explain the existence of the factor anomalies and whether the factors are prone to extreme downside risk. We document that the value, momentum, and local size effects in frontier markets cannot be explained by value, momentum, and local size effects in developed and emerging markets. This indicates that the excess returns are not caused by exposures to global risk factors and implies that our findings are independent of the existence of the effects in other markets. In addition we show that the downside risk of value, momentum and local size portfolios in frontier markets is lower than can be expected based on the assumptions of normality. Hence, we deem it unlikely that downside risk can explain the empirical results we document.

Our paper is organized as follows. We start in Section 2 by describing the data and methodology used in our analyses. We investigate the value, momentum, size and low-risk effect in more detail in Section 3. In Section 4 we incorporate transactions costs in order to determine whether the cross-sectional return patterns still exist when faced with real life market imperfections. In Section 5 we investigate whether value, momentum, and local size effects in frontier markets can be explained by global risk factors. Finally, Section 6 concludes.

\section{Data and methodology}

Our research on individual stocks in frontier emerging markets makes use of a unique data set with high quality data from different sources. In this section we describe our data collection procedure. 
All stocks are index constituents of the Standard \& Poor's Frontier Broad Market Index (S\&P Frontier BMI). The sample period runs from the inception of the index in January 1997 to November 2008, meaning our sample contains almost 12 years of data. The firm characteristics that we use to investigate the value effect are book-tomarket ratios, earnings-to-price ratios, and dividend yields. We use past local stock returns ranging from 6 to 36 months to investigate momentum ${ }^{6}$ and low-volatility strategies and past 36 months dollar stock returns to construct the beta strategy. We use market capitalizations to investigate the size effect.

\subsection{Sample selection}

Standard and Poor's (S\&P) selects the S\&P Frontier BMI constituents according to their country as well as according to company selection criteria. To select countries, they analyze potential frontier markets for investor interest and accessibility. A market's turnover, number of listings and whether it has attracted a minimum amount of foreign investor interest are considered. S\&P also considers a market's development prospects and, in particular, whether a market is likely to develop in breadth, depth and infrastructure. These requirements ensure that many small and inaccessible countries are not included in our data set.

In each country, S\&P selects the publicly listed equities, including local listings and listings from Hong Kong, London and New York, based on market capitalization and lack of foreign investment restrictions. The aggregation of the market capitalization of selected stocks should exceed $80 \%$ of the total market capitalization of each country. $\mathrm{S} \& \mathrm{P}$ reduces the number of shares outstanding used in the index calculation to reflect any limits or restrictions on investments by foreign investors or entities. Hence, our sample contains only the larger and more investable part of frontier equity markets. Our sample does not suffer from survivorship bias, as the index constituents are known real-time. Each month, we include only those stocks in our sample that are index constituents at that moment in time. ${ }^{7}$

\footnotetext{
${ }^{6}$ This is in line with Bhojraj and Swaminathan (2006), whose results suggest that using local returns for international momentum strategies leads to higher excess returns.

${ }^{7}$ Still, one could wonder whether the historical index has been constructed using future information. We verified with the IFC Emerging Stock Markets Factbook 1998 and the index construction
} 
Table 1 shows the frontier market countries in our sample with, in column two, the region classification and, in columns three to seven, country inclusion information: dates of inclusion in index, country index weights and number of firms at the moment of inclusion and as of the last sample month of October 2008. The largest countries (in terms of index weight) in October 2008 are Kazakhstan, Lebanon and Slovenia. During the sample period, the number of countries increased from 14 to 24, and the number of firms increased from 204 to 290. The last two columns contain the turnover ratio of stocks in a particular country in the inclusion year in the index and in 2008. The turnover ratio is a measure of liquidity and defined as the total value of stock trades in a year divided by the average market capitalization of the entire stock market. This data is obtained at the country level from the World Bank online database. ${ }^{8}$ The turnover rate for developed markets is typically between $50 \%$ and $150 \%$. For emerging markets the turnover rate is generally between $25 \%$ and $75 \%$. The turnover rate in frontier markets is on average close to $15 \%$, which is substantially smaller than for developed markets. In 2008, the frontier countries with the largest turnover ratios are Bangladesh, Tunisia, and Vietnam.

\section{$<<$ insert Table 1 about here $>>$}

\subsection{Returns and market capitalizations}

We calculate stock returns as monthly total returns in US dollars. Since S\&P does not provide total return data for individual stocks in frontier markets, we use total monthly returns from Interactive Data Exshare as our first data source. If total return data is not available from Exshare, then we aggregate S\&P monthly price returns and the cumulative daily dividend in that month divided by the price at the previous month-end to get monthly total returns. In case of extreme monthly return observations with large differences between the above two data sources, we check with alternative data sources, such as Bloomberg or the local stock exchange. ${ }^{9}$ If one of the total returns still cannot be confirmed, we use the smallest available in absolute

methodology by S\&P that no surviving countries were later added to the historical index. We also verified that no countries were excluded from the index during our sample period.

${ }^{8}$ Data retrieved from http://data.worldbank.org/indicator/CM.MKT.TRNR. Note that we cross-checked the data for 1997 with those available in the IFC Emerging Stock Markets Factbook 1998 and find that these are similar.

${ }^{9}$ We define monthly total returns larger than $100 \%$ and smaller than $-60 \%$ as extreme returns. 
value to limit the potential influence of outliers. To further gauge the quality of our data, we replicate the index returns for the individual countries in the S\&P Frontier BMI in US dollars and local currency using total returns, S\&P market capitalization, and index constituent identifiers in our individual stock database. The correlation between our replication and the index returns reported by S\&P is above $98 \%$. This high number gives us additional comfort that our data set is of high quality. Note that, in order to be eligible for inclusion in a portfolio, the stock needs to be included in the index. If a stock is in a portfolio and is taken out of the index, we still use its price return from the databases to calculate the portfolio return until the strategy excludes the stock from the portfolio. ${ }^{10}$

Table 1 shows information on return data per country and for the total market. The average monthly dollar return of the equally- and value-weighted frontier market portfolio equals $0.8 \%$. The difference between these two is not statistically significant (t-value 0.4). Nevertheless, it suggests that small capitalization stocks outperformed large capitalization stocks in our sample. The average return in frontier markets is higher than in developed and emerging markets over this sample period, where the average equally-weighted returns are respectively $0.5 \%$ and $0.6 \% .^{11}$ The standard deviation of the equally-weighted frontier markets index return is $4.2 \%$. This is marginally lower than the volatility of developed markets (4.4\%) and substantially lower than the volatility of the emerging markets index $(7.2 \%)$. Note that the low volatility in frontier markets is mainly due to low correlation among this group of countries. Individual country volatilities can be above $15 \%$ per month. ${ }^{12}$ The local returns are somewhat higher with $1.4 \%$ per month for the equally-weighted, and $1.1 \%$ per month for the value-weighted index. Volatilities for local returns are approximately the same as for the returns in USD.

\footnotetext{
${ }^{10}$ In most cases, stocks dropping from the index are not (immediately) delisted, limiting the concerns raised by Shumway (1997) on the potential effect of a delisting bias for US stock returns. For 20 individual stocks, we observe monthly returns below $-90 \%$, indicating severe stress for the companies involved. These negative returns are included in the portfolio returns. Nevertheless, despite extensive data checks, we cannot guarantee that there are some individual cases for which delisting returns are not accurately accounted for in our databases.

${ }^{11}$ The developed markets universe consists of stocks included in the FTSE World index and for emerging markets it is stocks in the S\&P/IFCI Emerging Markets index.

${ }^{12}$ Erb, Harvey, and Viskanta (1996) predict the risk of equity markets in 135 countries. For the frontier markets, they predict $8-14 \%$ volatility on a monthly basis. This is roughly in line with our summary statistics in Table 1 for the individual countries.
} 
In addition, we present median market capitalizations in Table 1. We can see that the median firm size of frontier market stocks is USD 36 million. This is substantially lower than in emerging markets (EM) where the median firm size is approximately ten times larger at USD 337 million.

\subsection{Accounting data}

For the firm characteristics book-to-market and earnings-to-price ratio, we use S\&P as our first data source. If for a particular stock $S \& P$ data is not available, we use Worldscope data, which we lag with 6 months to account for delayed availability of the annual reports. We extract dividend yield data from the Interactive Data Exshare database, which we calculate as the cumulative daily dividend payments over the past twelve months, divided by the price at each month-end.

We check the data quality of each of these variables using various statistics, such as coverage, median, maximum value and minimum value in each month during our sample period. In addition, we examine alternative data sources, such as Bloomberg, in the case of suspicious values. This battery of quality checks has led to a unique, high-quality frontier emerging markets data set.

We summarize these firm characteristics of our sample data with statistics in Table 1. The median book-to-market ratio is 0.8 (EM 0.6), the median earnings-to-price ratio 8.5\% (EM 6.1\%) and the median dividend yield 2.5\% (EM 1.7\%). Based on these value characteristics, frontier market stocks are considered to have been cheaper than emerging markets stocks over this sample period. Kazakhstan and Panama do not have any dividend yield data, as they only entered the index in December 2007 and have a history of less than one year. Furthermore, for the entire sample of frontier markets, approximately one-third of the stocks have a dividend yield equal to $0 \%$.

\subsection{Data coverage of stock and firm characteristics}

Figure 1 presents the number of S\&P Frontier BMI constituents through time and the number of firms that have data available for the different characteristics. The number of index constituents is stable, with 204 at the start and varying between 250 and 300 over our sample period. There were 290 stocks at the end of the sample period in October 2008. Since stocks enter and exit the index, the total number of individual 
stocks over the entire sample period is slightly more than 1,400. For each stock, the market capitalization is available. For the return-related variables we show only the coverage of 1 -month momentum, for which we have almost $100 \%$ data coverage. ${ }^{13}$ The coverage of the book-to-market and earnings-to-price ratio is almost $100 \%$ before 2007, and slightly decreased thereafter, because our data sources do not provide information for several stocks that newly entered the index. Dividend yield is the characteristic with the lowest data coverage, as it depends on a single data source. Nonetheless, dividend yields are available for at least 200 firms in most of the months of the sample period, meaning that the average coverage is above $80 \%$.

\section{$<<$ insert Figure 1 about here $>>$}

We conclude that the data coverage and quality is sufficiently high to examine the profitability of investment strategies in frontier markets.

\subsection{Portfolio construction methodology}

We form investment portfolios in a style similar to, e.g., Jegadeesh and Titman (1993). At the end of each month, we rank the stocks on a particular characteristic. ${ }^{14}$ For our baseline strategy, we form an equally-weighted portfolio from the top $20 \%$ of the ranking, label this the Top portfolio, and compare these with the equally-weighted average return from the entire sample, the Index portfolio. We additionally create an equally-weighted portfolio from the least attractive $20 \%$ of stocks, and label this the Bottom portfolio to investigate long-short strategies. For most frontier equity markets it is nearly impossible to short sell stocks. However, in a portfolio management context, the short portfolio can be used to underweight assets relative to the frontier market benchmark index. A lower portfolio weight than in the benchmark index means in essence a short position for the portfolio manager. Note that these short positions in the benchmark in this context are capped at the benchmark weight, while

\footnotetext{
${ }^{13}$ To prevent losing three years of our sample for the 36-month momentum and low-risk variables, we assume an expanding window in the beginning of our sample period starting with 12 monthly return observations.

${ }^{14}$ Note that we treat companies that pay no dividend at all separately when calculating the excess return for the D/P strategy. We treat them in the same way as firms with missing data and rank them in the middle, so that it does not appear in the top or bottom portfolio that month. This methodology of dealing with companies that pay no dividend and the empirical results are in line with Fama and French (1993).
} 
for long-short portfolios these weights are (in theory) uncapped. For small-cap stocks such long-only constraint is most problematic, as short positions relative to the benchmark are by definition small. For this reason, the main focus in all our analyses is on the top portfolio. Each month, new portfolios are constructed, which we hold for a period of twelve months, unless a stock gets delisted before the end of the holding period. These stocks exit the relevant portfolio, and the weights of the remaining stocks are adjusted proportionally.

As we construct new portfolios every month and use a 12-month holding period, at any point in time the strategies effectively hold stocks from twelve portfolios, each formed one month apart. We calculate monthly returns for a particular strategy as the average of the returns of the twelve portfolios. All returns are expressed in US dollars. For country- or region-neutral portfolios, we rank the stocks within each country on a characteristic and assign the top $20 \%$ of each country to the Top portfolio. Hence, the country-neutral Top portfolio has the same country distribution as the Bottom portfolio and the Index portfolio. An additional side-effect is that country-neutral portfolios contain the same percentage of stocks in a certain currency as the bottom or index portfolio and therefore the associated excess returns cannot be attributed to currency movements.

\section{Value, momentum, size, and low-risk effects in frontier markets}

In this section, we analyse the cross-section of returns on four common types of characteristics on which we have high-quality data available for our frontier emerging markets. First, we investigate three valuation characteristics, followed by an investigation of three momentum characteristics. We continue with firm size as measured by market capitalisation and end with two low-risk characteristics. We continue the section by analysing the impact of capital constraints on the results and conclude by investigating the diversification benefits between the three types of characteristics.

\subsection{Value}


We start by investigating value investment strategies for which Fama and French (1992) and Lakonishok, Shleifer, and Visney (1994) report significantly positive excess returns for US stocks. Fama and French (1998) and Rouwenhorst (1999) find out-of-sample evidence for international developed and emerging equity markets. We rank the cross-section of stocks in our sample on three value characteristics: the bookto-market ratio $(\mathrm{B} / \mathrm{M})$, earnings-to-price ratio $(\mathrm{E} / \mathrm{P})$, and dividend-to-price ratio $(\mathrm{D} / \mathrm{P})$. Stocks with high $\mathrm{B} / \mathrm{M}, \mathrm{E} / \mathrm{P}$, and $\mathrm{D} / \mathrm{P}$ ratios have on average higher returns than stocks with low ratios. This is called the value effect.

\section{$<<$ insert Table 2 about here $>>$}

The left part of the results in Table 2 indicates that our sample of frontier market stocks also exhibits strong value effects. The first row in Table 2 indicates that $\mathrm{B} / \mathrm{M}$ sorted portfolios have a Top-Minus-Index (TMI) excess return of $0.74 \%$ per month, which is statistically significant with a t-value of 3.05. ${ }^{15}$ For portfolios ranked on E/P, we find economically and statistically significant TMI returns of $1.26 \%$ per month with a t-value of 5.55. The $\mathrm{D} / \mathrm{P}$ valuation strategy has the least positive excess returns, with $0.41 \%$ per month and a t-value of 1.72 .

We also investigate the average return of Top-Minus-Bottom (TMB) portfolios. Table 2 shows that the documented excess return of the B/M strategy is almost equally split between the long and the short side, as the return of the $\mathrm{B} / \mathrm{M}$ factor of $0.74 \%$ is roughly doubled to $1.66 \%$ when viewed in excess of the bottom portfolio. We find comparable results for E/P and D/P. Due to the increased volatility of this Top-MinusBottom strategy, the t-values increase to a lesser extent and decrease somewhat for $\mathrm{E} / \mathrm{P}$.

We compare our results to Top-Minus-Bottom returns of more developed equity markets. Fama and French (1998) report $0.64 \%$ excess return per month for B/M, $0.57 \%$ for $\mathrm{E} / \mathrm{P}$, and $0.46 \%$ for $\mathrm{D} / \mathrm{P}$ for a global equity portfolio consisting of 13 countries over the period 1975 to 1995. They furthermore show that the value premium exists for most countries individually and are not limited only to the US.

\footnotetext{
${ }^{15}$ Throughout our paper, we use the method described in Newey and West (1987) to calculate t-values that are robust to heteroskedasticity and autocorrelation.
} 
Rouwenhorst (1999) reports a $0.72 \%$ per month excess return for B/M for stocks in 20 emerging markets over the period 1987 to 1997, and Van der Hart, De Zwart, and Van Dijk (2005) report $0.73 \%$ and $0.68 \%$ per month excess return for $\mathrm{B} / \mathrm{M}$ and $\mathrm{E} / \mathrm{P}$ in 31 emerging markets over the period 1988 to 2004. Thus, the excess returns based on value-characteristics sorted investment strategies in frontier markets are economically at least as large as those reported in the literature for developed and emerging stock markets.

As our results might be driven by frontier market risk, we also calculate the alphas relative to a single-factor model with the equally- or value-weighted frontier market index as the single risk factor. The betas of the TMI strategies are close to zero for each of the value strategies (not reported). This implies that the alphas reported in Table 2 ('market risk adjusted') here are close to the raw TMI returns reported before. For example, the $0.74 \%$ raw excess return of the $\mathrm{B} / \mathrm{M}$ strategy is slightly reduced to a significant risk-adjusted alpha of $0.69 \%$ per month when we use an equally-weighted market index and stays $0.74 \%$ per month when we use a value-weighted market index. An important exception is the D/P strategy. This strategy selects stocks with a relatively low beta to the market index. ${ }^{16}$ Hence, the market risk-adjusted excess return is $0.59 \%$ ( $\mathrm{t}$-value 3.00 ) per month for an equally-weighted index and $0.50 \%(\mathrm{t}-$ value 2.43) per month for a value-weighted index, whereas the raw excess return was only $0.41 \%$ (t-value 1.72 ). Summarizing, our results indicate that unconditional beta risk cannot explain the excess returns on the investment strategies. This observation is in line with results documented for these strategies in developed and emerging equity markets.

As these investment strategies rank all stocks at each period in time, the raw results reported in the first row of Table 2 might be influenced by regional effects. In other words, the top portfolio might be more exposed to certain regions than the index which could explain part of the abnormal returns. Therefore, we also calculate each of the investment strategies per region and also display the region-neutral TMI investment strategies in the second part of Table 2. These investment strategies require the $20 \%$ most attractive stocks from each region to be in the top portfolios,

\footnotetext{
${ }^{16}$ Fama and French (1998) also report that the global high D/P strategy has a beta of 0.87, lower than the beta of the $\mathrm{B} / \mathrm{M}$ and $\mathrm{E} / \mathrm{P}$ strategy, which are 0.94 and 0.95 , respectively.
} 
which ensures that the regional distribution of the top portfolio is equal to the index. ${ }^{17}$ The results in Table 2 indicate that the results are not driven by regional effects. The region-neutral strategy yields value returns of $0.73 \%(\mathrm{~B} / \mathrm{M}), 1.08 \%(\mathrm{E} / \mathrm{P})$, and $0.56 \%$ (D/P) per month, which are all statistically significant and similar in magnitude as the non-neutral returns. We document a positive TMI return for most of the valuation characteristics of each of the regions separately. The D/P strategy seems to be the weakest valuation variable where both Europa and Asia have negative returns. These low returns for the long-only D/P strategy is caused by its low beta, as we also saw for the non-neutral strategy. Summarizing our region-neutral results, we conclude that the presence of the value effect is robust to regional influences.

While the value effect is present across regions, it is possible that differences in country-specific accounting standards or currency effects might drive our results, at least to some extent. Therefore, we take the analysis one step further and calculate country-neutral investment strategies. In this way, country and currency effects are hedged out relative to the index, as explained in Section 2.5 on the portfolio construction methodology. Table 2 shows that imposing country neutrality does not alter our conclusions about the significant presence of value effects in frontier markets. Nevertheless, part of the global TMI returns can be attributed to country allocation, as TMI returns for the country-neutral strategy are about half of the noncountry-neutral returns. Our finding that part of the value effect is driven by country allocation is in line with Asness, Moskowitz, and Pedersen (2009), who report that ranking country indexes based on valuation measures leads to significant excess returns. This analysis shows the benefits of using stock-specific data as our results indicate that valuation measures at the individual stock level contain information above and beyond the country level which is vital to fully capture the factor return.

The analyses in this sub-section show that the value effect is robust and strongly present in our data set consisting of frontier emerging equity stocks.

\subsection{Momentum}

\footnotetext{
${ }^{17}$ The number of stocks is not exactly equal with or without region or country neutrality imposed, as we require each region or country to have at least 4 stocks available and data coverage of at least $40 \%$ at a point in time to be included in the analysis. The average number of stocks in the strategy per region is as follows: America 35, Europe 103, Africa 80, Asia 49.
} 
In this section, we investigate the profitability of momentum strategies in frontier emerging markets. This means that stocks in the cross-section are ranked on their past returns. Stocks with higher past returns are expected to have higher future returns. Jegadeesh and Titman (1993) report significantly positive excess returns for winner stocks relative to loser stocks over the past 3 to 12 months in the US, and Rouwenhorst $(1998,1999)$ confirms these findings for international developed and emerging market stocks.

In Table 2 we display momentum strategies with a look-back period of 3, 6, and 12 months, and a holding period of 12 months. Similar to the value strategies, we choose a relatively long holding period of 12 months as we know that transactions costs can be substantial in frontier emerging markets. ${ }^{18} \mathrm{We}$ see that the 3-month look-back period results in a $0.95 \%$ per month excess return relative to the index. For longer look-back periods the excess returns are smaller, with $0.59 \%$ per month for a 12 month look-back period. In order to compare our results to the literature, we also display how much excess returns the short positions generate and how this adds up to returns of the Top-Minus-Bottom portfolios. In all cases, the results are stronger for the top than for the bottom portfolio. TMB returns are higher than for TMI, but with lower t-values. For the 6-month momentum strategy, e.g., we obtain a $1.19 \%$ per month excess return with a t-value of 2.80 for the TMB portfolio compared to an excess return of $0.77 \%$ per month with a t-value of 4.02 for the TMI portfolio.

The magnitude of our momentum profits in the medium term is in line with those observed for developed and emerging markets. Jegadeesh and Titman (2001) report an excess return of $1.09 \%$ per month for past 6-month winners relative to losers for the US over the period 1965 to 1997 . Rouwenhorst $(1998,1999)$ documents $1.16 \%$ per month for European stock markets (1980-1995) and 0.39\% per month for emerging markets (1982-1997). Van der Hart, De Zwart, and Van Dijk (2005) report $0.74 \%$ for their sample of 31 emerging markets over the period 1988 to 2004 . The short-term momentum returns are in line with Chan, Hameed, and Tong (2000), who report a $1.1 \%$ per month excess return for short-term country momentum strategies using a sample of 23 developed and emerging countries over the period 1980 to 1995.

\footnotetext{
${ }^{18}$ In Section 4 we investigate the sensitivity of value and momentum effects to other holding periods.
} 
We conclude that the excess returns from our frontier equity markets momentum strategies are economically at least as strong as those reported previously for developed and emerging equity markets.

We also calculate the alphas relative to a single-factor model with the equallyweighted and value-weighted frontier market index as the risk factor. The betas of the TMI strategies are close to zero for each of the excess returns of the momentum strategies (not reported). This implies that the alphas reported in Table 2 are about the same as the raw TMI returns reported before. Hence, these results indicate that unconditional beta risk cannot explain the excess returns of the momentum investment strategies. This is in line with results documented for momentum strategies in developed and emerging equity markets.

In the second part of Table 2 we investigate in more detail the influence of regional and country effects on the return of momentum strategies. We see that the raw momentum returns slightly decrease when we impose region neutrality. For example, the 6-month momentum strategy decreases from $0.77 \%$ per month to $0.69 \%$ per month. For all momentum strategies, each of the regions separately also have a positive excess return. Particularly for the 6-month momentum strategy we find the strongest results for Africa ( $0.94 \%$ per month) and the weakest for America $(0.31 \%$ per month). Imposing country neutrality further reduces the momentum profits, although only for the 12-month momentum strategy we do not find significant results anymore. The 6-month momentum profits reduce to $0.21 \%$ per month, implying that country momentum is part of the total momentum profit. Rouwenhorst (1998), Chan, Hameed, and Tong (2000) and Bhojraj and Swaminathan (2006) provide empirical evidence of momentum profits at the country level for developed and emerging equity markets. Our results confirm the existence of country momentum within the group of frontier markets and may serve as out-of-sample evidence for what is sometimes called macro-momentum, since it is at the country level. 
Chui, Titman, and Wei (2010) link the existence of the momentum effect to the degree of individualism of investors within a country. ${ }^{19}$ Their results suggest that countries with a high Hofstede score on individualism also earn higher average momentum returns. ${ }^{20}$ For several of the frontier markets countries, a score on individualism is available; see Hofstede (2001) and Appendix B. The average score is low for frontier markets for which the score is available. A low score suggests that social groups such as families play a more important role than individuals. Chui, Titman, and Wei (2010) claim that the medium-term momentum effect is weaker for countries with low individualism. The low individualism score for frontier markets would imply that momentum effects in these markets are rather small. Hence, we investigate the momentum returns for the sub-sample of countries with a low individualism score. Estonia, Jamaica, Lebanon, and Slovakia are excluded because they have an individualism score above the threshold of the low individualism subsample from Chui, Titman, and Wei (2010). From the last row of Table 2, we observe that the momentum returns from our low individualism sub-sample are at least as high as those in the full sample. Hence, our results do not seem to indicate that momentum is weak in countries with a low score on cultural individualism.

The analyses in this sub-section show that the momentum effect is robust and strongly present in our data set consisting of frontier emerging equity stocks.

\subsection{Size}

The size effect means that the cross-section of stocks is ranked according to market capitalization of equity. Stocks with a relatively low market capitalization experience higher returns than stocks with a relatively large market capitalization. The existence of the size effect has been first documented by Banz (1981) for US equity markets and has later been confirmed by many other researchers in equity markets around the world. Van Dijk (2011) provides a comprehensive review on the size effect around the world.

\footnotetext{
${ }^{19}$ Speidell (2009) reports some anecdotal evidence of differences in investor behavior in frontier markets.

${ }^{20}$ See www.geert-hofstede.com for detailed information on the scores on different aspects of culture.
} 
Table 2 indicates that we do not find a size effect among the total group of frontier emerging markets countries. The excess return of a portfolio of stocks with a small market capitalization relative to the index is an insignificant $0.23 \%$ per month. Also, small capitalization stocks do not significantly outperform large capitalization stocks, as the return of the Top-Minus-Bottom portfolio is $0.51 \%$ with a t-value of 1.19 .

Our results on a region and country-neutral level indicate that the size effect is a local effect. In three out of four regions the return of small stocks is higher than that of the index. Due to diversification benefits across regions, the region-neutral size effect is economically and statistically significant with an excess return of $0.81 \%$ per month and an associated t-value of 3.64. Imposing country-neutrality leads to qualitatively similar results as imposing region-neutrality. The finding of only a local size effect again emphasizes the need of individual stock data to fully capture the return premium related to the size factor, as the country allocation decision does not seem to add significant value.

These results are in line with the empirical literature on the international existence of the size effect. For example, Heston, Rouwenhorst, and Wessels (1999) report a significant size effect in Europe, which is due to small stocks within a country earning higher risk-adjusted returns than large stocks within the same country. Barry, Goldreyer, Lockwood, and Rodriguez (2002) also only find evidence of a size effect in emerging markets when they measure size relative to the local market. The size effect in Rouwenhorst (1999) is significant in 12 out of 20 individual emerging markets.

The analyses in this sub-section show that only the local size effect is present in our data set consisting of frontier emerging equity stocks. For that reason we only focus on the local size factor in the remainder of the analyses.

\subsection{Low-risk}

Another factor that is difficult to reconcile with the CAPM is the low-risk effect. This factor is constructed by ranking stocks on historical risk measures, such as beta or volatility. To our knowledge, Black, Jensen, and Scholes (1972) are the first to 
document the abnormal returns of these low-risk portfolios. Later, Blitz and Van Vliet (2007) documented that low-risk stocks have alpha relative to the CAPM not only in the US, but also in international markets. There are at least three explanations put forward for the existence of the low-risk effect. First, investors might not be allowed to or willing to apply leverage to their investment portfolio. When they wish to increase expected returns without employing leverage they are forced to buy high-risk stocks (under the assumption that expected returns and risk are positively correlated); see Black (1972), Falkenstein (2009), and Baker, Bradley, and Wurgler (2011). Second, the existence of the low-risk effect might be caused by a two-step investment process. In the first step the asset allocation decision is taken by the chief investment officer using absolute risk and return criteria. In the second step, investment managers are hired to outperform a benchmark, causing them to focus on relative risk and return criteria. Such delegated portfolio management decisions may lead to suboptimal portfolios and may distort aggregate asset prices in such a way that high-risk assets are structurally overpriced and low-risk assets structurally underpriced; see Van Binsbergen, Brandt, and Koijen (2008). Thirdly, Shefrin and Statman (2000) suggest that private investors may hold part of their wealth, above a certain threshold level, as a gamble to quickly become rich. This might explain why many private investors only hold a limited number of stocks in their portfolio. This behavioral effect might lead highly volatile stocks to be overpriced.

In Table 2, we display the returns of a portfolio of low-beta stocks and low-volatility stocks. For the TMB portfolio this is the low-beta (low-volatility) portfolio minus the high-beta (high-volatility) portfolio. Both risk measures beta and volatility are calculated using historic 36 month returns. The empirical results in Table 2 indicate that we do not find a strong low-risk effect in frontier emerging markets countries. The excess return of a portfolio of stocks with a low-volatility relative to the index is an insignificant $0.07 \%$ per month, whereas low-beta stocks underperform the index by an insignificant $0.32 \%$ per month. As risks are persistent, portfolios formed on lowrisk characteristics are also in the investment period less risky than the index. Hence, it makes more sense to look at risk-adjusted returns than absolute levels of return. We see that the low-volatility effect, with an alpha of $0.41 \%$ per month relative to the equally-weighted index, is economically and statistically significant. However, this result is not robust. For other specifications, for example using low-beta instead of 
low-volatility or measured against a value-weighted index, the results are not statistically significant. For our region- or country-neutral analyses, we occasionally find a significantly positive relation between risk and return as one would expect from standard textbook finance.

Blitz, Pang, and Van Vliet (2012) suggest that low-risk strategies also earn higher risk-adjusted returns in emerging equity markets. However, they observe that in the first half of their sample (1989-1999) the low-risk effect in emerging markets is weaker than in the second half of their sample (2000-2010). They attribute this to the lack of benchmark-driven investors in the first half of their sample. We expect that for frontier markets over our sample period the number of benchmark-driven investors is limited, and only recently has started to become an asset class that institutional investors might allocate to. If the conjecture of Blitz, Pang, and Van Vliet (2012) is correct, we also expect a small low-risk effect in our sample. Our results seem consistent with their explanation. This means that our findings casts doubt on the explanation that the low-risk effect is caused by market frictions such as short sales constraints, which are more likely to exist in frontier markets.

The analyses in this sub-section show that the low-risk effect is neither statistically nor economically significant in our sample of frontier emerging equity stocks. For that reason, we only analyse the value, momentum and local-size strategies in subsequent sections.

\subsection{Influence of capital constraints}

The empirical results on the value, momentum, and local size effect that we displayed in Table 2 could be related to capital constraints in frontier equity markets, as these markets have not always been as open as they currently are. Although our data provider takes these requirements into account before admitting a country to the frontier markets index, the investment strategies could potentially still be tilted towards countries with the most or least investment restrictions in our sample. ${ }^{21}$ Although a priori it is not clear what the effect would be of this tilt, we want to make sure that our findings are robust in this respect. Therefore, we use data on financial

\footnotetext{
${ }^{21}$ Note that unreported empirical results indicate that the average returns of the frontier emerging markets are not related to their average financial market liberalization score or the change thereof.
} 
market liberalization to separate the frontier markets into a most and least liberalized group and verify whether our results still hold for these sub-samples. ${ }^{22}$

We use three different measures of financial market liberalization, namely relevant sub-indices of the Index of Economic Freedom reported by The Heritage Foundation $(\mathrm{HF})^{23}$, the KOF Index of Globalization constructed by the ETH Zurich $(\mathrm{KOF})^{24}$ and the Economic Freedom of the World (EFW) reported by the Fraser Institute. ${ }^{25} \mathrm{We}$ choose sub-indices in such a way that they best represent investment freedom. ${ }^{26}$ The higher the score, the higher the financial liberalization, meaning it is less likely that capital constraints play an important role in that country. We omit scores when a country is not yet included in the S\&P Frontier BMI. For all three indices the coverage is high, although not all data is always available, such as KOF and EFW data for Lebanon. As can be expected, the rank correlations between these indices are relatively high with roughly $75 \%$ over the sample period. Nevertheless, some differences are present and therefore we investigate the impact of each of the three measures separately.

At the end of each month, we rank all countries based on each of the three financial liberalization indices. ${ }^{27}$ We choose the thresholds to split the countries into a most and least liberalized group in such a way that the two groups contain approximately an equal number of stocks. We then form investment portfolios on the most and least

\footnotetext{
${ }^{22}$ See Bekaert and Harvey (2003) for an overview on integration and liberalization measures for emerging markets. Unfortunately, Bekaert and Harvey $(1995,2000)$ do not have integration data available for the frontier equity markets in our sample.

${ }^{23}$ Data are available at http://www.heritage.org. We use the average of the sub-indices Financial Freedom and Investment Freedom, as these two are closest to the definition of freedom that we prefer to measure for our analyses.

${ }^{24}$ Data available at http://globalization.kof.ethz.ch. For more details on this index: see Dreher (2006). We use the Economic Globalization dimension scores, as the Political and Social Globalization dimensions are less relevant for our analyses.

${ }^{25}$ Data from the Fraser Institute available at http://www.freetheworld.com. We use the area Freedom to Trade Internationally as this area most directly represents the measure we are interested in.

${ }^{26}$ Appendix A contains the annual scores per frontier country and a comparison of the liberalization measures for frontier markets with developed and emerging countries.

${ }^{27}$ We incorporate appropriate time lags when using the index scores. Heritage Foundation informed us that annual scores have become available in the first quarter. Therefore we use the scores as of the end of March every year. KOF data has become available every year around January based on data of two years ago. So, around January 2008, the new index became available based on 2005 data. To be conservative, we use a two years and one quarter lag, meaning we assume 2005 data is available at the end of March 2008. Note that this index contains a look-ahead bias, as data of previous years changes with the introduction of a new methodology. The same holds for EFW, although data becomes available a bit earlier. We use a one year and three quarters lag, meaning that we assume 2005 data is available at the end of September 2007.
} 
liberalized stocks separately. The bottom part of Table 2 contains the results for the sub-samples with the highest and lowest financial liberalization according to each of these measures. With the exception of the D/P factor, which also showed the weakest overall results, we observe that value strategies still deliver significantly positive excess returns in liberalized as well as non-liberalized countries, both from an economic and statistical point of view. Therefore, we conclude that capital constraints do not seem to drive the value effects. We also check the influence of capital constraints of each of the countries on our momentum results and on the countryneutral size results. These strategies all still deliver substantial positive excess returns in both liberalized and non-liberalized sub-samples. ${ }^{28}$ Therefore, we also conclude that capital constraints do not seem to drive momentum and size returns.

\subsection{Diversification effects}

Asness, Moskowitz, and Pedersen (2009) indicate that value and momentum strategies are negatively correlated within asset classes. This negative correlation implies diversification benefits from combining value and momentum effects in one investment strategy. We therefore investigate the correlation between the three value strategies, the three momentum strategies, and the local size strategy that we analyzed before.

\section{$<<$ insert Table 3 about here $>>$}

In Table 3, the correlations over the period 1997 to 2008 are displayed. The momentum strategies are all positively correlated, ranging from 0.35 to 0.75 for different formation periods. The correlation between valuation strategies is mixed. $\mathrm{B} / \mathrm{M}$ and $\mathrm{E} / \mathrm{P}$ strategies are positively correlated with a coefficient of 0.47 . The $\mathrm{D} / \mathrm{P}$ strategy is negatively correlated to the $\mathrm{B} / \mathrm{M}$ strategy and uncorrelated to the $\mathrm{E} / \mathrm{P}$ strategy. Our empirical results suggest that combining different valuation indicators improves the risk-adjusted performance of a long-only valuation investment strategy.

\footnotetext{
${ }^{28}$ Our proxies are related to capital constraints, which could be related to more practical difficulties for international investors. These measures of capital constraints could therefore also be interpreted as efficiency measures. Griffin, Kelly, and Nadari (2010) suggest that traditional return-based efficiency measures, such as variance-ratio tests, are not related to the magnitude of momentum returns in 56 developed and emerging markets.
} 
The off-diagonal block of the correlation matrix indicates that valuation strategies are on average unrelated to the momentum strategies with correlations ranging from -0.25 between $\mathrm{B} / \mathrm{M}$ and 12-month momentum to 0.20 between $\mathrm{E} / \mathrm{P}$ and 3-month momentum. Hence, the diversification benefits between value and momentum within frontier markets are large. The size strategy is also virtually uncorrelated with value and momentum strategies, indicating that diversification benefits also exist with the size factor.

\section{Incorporating transaction costs}

The results in the previous section are based on market prices without taking transaction costs explicitly into account. Fortunately, our data provider S\&P explicitly takes liquidity into account when deciding to include a country or a stock in their frontier markets index. Hence, we expect that the stocks in our sample can be traded in reasonable quantities. ${ }^{29}$ Furthermore, our results in Section 3.5 already indicate that for our sample of stocks, constraints on the free movement of capital into frontier countries does not explain the existence of the value and momentum effects. Nevertheless, actual transaction costs, such as bid-ask spreads, market impact costs and commissions might be a particular issue for frontier markets, as liquidity is typically lower than for more developed equity markets (see, e.g., Speidell and Krohne 2007) as indicated in Table 1. This raises the question on whether the abnormal returns associated with value and momentum investment strategies are truly inconsistent with market efficiency. In this section we analyze the profitability of the investment strategies when faced with real life market imperfections.

Not much has been documented on actual trading costs in frontier markets. Papers that examine stock market anomalies after incorporating trading costs in U.S. markets often make use of the model of Keim and Madhaven (1997), see e.g. Avramov, Chordia and Goyal (2006). However, as this model is only calibrated on the U.S. market it can therefore not be applied to frontier markets. Recently, Marshall, Nguyen, and Visaltanachoti (2011) estimated the transactions costs for a sample of 19 frontier markets stocks using data over the period 2002 to 2010 from Thomson

\footnotetext{
${ }^{29}$ See Lesmond (2005) and Bekaert, Harvey, and Lundblad (2007) for a detailed investigation of liquidity in emerging markets.
} 
Reuters Tick History database. They report average value-weighted effective spreads of $0.95 \%$ and market impact costs of $0.45 \%$ over their sample period.$^{30}$ Furthermore they use commission data based on Quisenberry (2010) which the author estimates to be $1.09 \%$ on average in 2007 . We therefore assume total single-trip transaction costs of $2.5 \%$ for each stock in our analysis which is equal to the sum of the spread between mid and bid/ask price, market impact, and commission costs. This estimate for frontier emerging markets is substantially larger than recent estimates for more developed equity markets. E.g., De Groot, Huij and Zhou (2011) report average transaction costs estimates incorporating spread, market impact and commissions of 9 basis points for S\&P 500 stocks over the period 1990 to 2009 and 26 basis points for the 600 largest European stocks over the same sample period. This means that our assumption of transaction costs is 28 times larger than the US estimates and 10 times larger than the European estimates. Although our sample seems to be more liquid than that of Marshall, Nguyen, and Visaltanachoti (2011), we prefer to be conservative and apply these cost estimates only to the largest 150 stocks in our sample. In Figure 1 we showed that our sample consists of approximately 300 stocks at each point in time, which means that we disregard the smallest half of our sample in our analysis in this section. An additional important trading cost component in frontier markets are opportunity costs, since finding a counterparty to trade with might not be that easy in frontier markets. As a consequence, we therefore skip one month between ranking and portfolio formation. This means that an investor may spend a whole month searching for a counterparty to trade with.

\section{$<<$ insert Table 4 about here $>>$}

The results in Table 4 incorporate transaction costs in the value and momentum investment strategies. We do not include the size effect here for two important reasons. First, the size effect is defined as the excess returns of small caps versus large caps. We focus on the largest 150 stocks in our analysis after transactions costs, which excludes investigating the small cap effect as this requires trading in the smallest stocks of our sample. Second, our estimates on transaction costs are conservative for

\footnotetext{
${ }^{30}$ In addition, we asked a large stock broker (Nomura) for estimates on bid-ask spreads in frontier markets. They find that these spreads are generally below 1\%, confirming the results by Marshall, Nguyen, and Visaltanochoti (2011).
} 
our sample of large cap stocks. It is less clear what the trading costs in practice may be for a portfolio of small cap stocks. Hence, we decide to focus only on value and momentum strategies in this section.

Panel A of Table 4 contains the results based on a 12-months holding period. The first row in the panel contains the gross returns of each of the effects based on the sample of 150 largest stocks and with a one-month skip between ranking and implementation. Although these raw returns are slightly smaller in magnitude compared to those reported in Table 2 on the entire sample and without assuming an implementation lag, the returns are still statistically significant. For example, the B/M strategy yields a $0.66 \%$ per month excess return versus a $0.74 \%$ that we saw before on the entire sample. Hence, the gross returns are somewhat smaller in magnitude as we reported before, but are less likely to incur substantial transactions costs. Only for dividend yield we find a significant improvement from $0.41 \%$ per month (t-value of 1.72 ) to $0.74 \%$ per month (t-value of 3.47). Omitting the small cap stocks from our analysis leads to a larger beta of the D/P strategy compared to our results on the whole sample reported in Section 3.1 .

The remainder part of Panel A of Table 4 contains the excess returns of the top portfolio after incorporating transaction costs compared to the equally-weighted index return. More precisely, at the end of every 12-month holding period we investigate which stocks exit and enter the portfolio, multiply this total turnover weight by $2.5 \%$ single-trip trading costs and subtract it from the gross return of that portfolio in that month. The second row in the panel assumes a theoretical equally-weighted index that we assume can be invested in against zero costs. However, more realistic would be to evaluate the profitability of anomalies against an index net of transaction costs which could be seen as the passive alternative of the trading strategies. The third row in the panel displays the excess returns of the strategies relative to the index return where we assume that stocks entering and leaving the index also incur the same transactions costs as for the stocks in our trading strategies. The one-way turnover of the benchmark is relatively high with approximately $2.5 \%$ per month which leads to about 12 basis points difference in returns between the gross and net benchmark. 
When we focus on the value strategies with a 12-month holding period we observe in the last row of the panel that the one-way turnover is ranging from $4.8 \%$ to $5.6 \%$ per month (or $57 \%$ to $67 \%$ per year), indicating that not all stocks have to be traded at the end of the holding period. Some value stocks remain value stocks, not inducing a trade after 12 months. This turnover leads to a decrease in returns of 10 to 14 basis points per month when compared to a net benchmark and 22 to 26 basis points per month when compared to a gross benchmark. Still, we observe economically and statistically significant returns of approximately $6.6 \%$ to $7.7 \%$ per annum after incorporating transactions costs compared to a net benchmark. ${ }^{31}$ Momentum returns are less robust to transactions costs than valuation strategies. The turnover of these strategies is higher than for valuation strategies with almost $7 \%$ per month (or around $80 \%$ per year), and in combination with lower gross excess returns the 12-month momentum strategy is no longer statistically significant. However, also the net returns of $4.6 \%$ and $7.2 \%$ per annum for respectively the 6-month and 3-month momentum strategy compared to a net index indicates that also these strategies are economically and statistically significant.

In addition to the 12-month holding period, Table 4 also contains the after transaction costs returns of the same investment strategies with holding periods ranging from 6 months to 24 months in Panel B to D. Shorter holding periods imply more aggressive trading when a stock drops out of the top $20 \%$ portfolio. However, gross returns are also likely to be higher. We investigate the trade-off between turnover and gross returns by examining the net returns of the strategies with different holding periods. Since valuation characteristics do not change significantly over time, we see that the turnover increases to approximately $7 \%$ to $8 \%$ per month for a 6 -month holding period, and declines to approximately $3 \%$ for a 24 -month holding period. Simultaneously, we observe that the gross returns of the value strategies remain relatively stable for different holding periods. This analysis indicates that the holding period matters for the net returns of an investor. Investors that try to capture the value effect in frontier markets might prefer to hold stocks somewhat longer than the 12 months that we use in our standard analysis, as net returns do not seem to decrease for longer holding periods. Momentum strategies are more dynamic by nature, which

\footnotetext{
${ }^{31}$ This is at odds with Houge and Loughran (2006), who suggest that the value effect is driven by stocks with little liquidity and hence cannot be exploited by investors.
} 
results in higher trading activity for shorter holding periods. A strategy with a 6month formation and holding period yields $12.7 \%$ turnover per month. This eats up about one half of the gross excess returns. Holding periods longer than 12 months lead to lower turnover, but also to lower gross returns, which results in lower net returns. We find that only momentum strategies with a 3-month formation period remain economically and statistically significant for holding periods longer than one year. We conclude based on this analysis, that the optimal holding period for momentum strategies is around 6 to 12 months.

The findings above indicate that the value and momentum effects still exist when incorporating conservative assumptions of transaction costs and therefore seem to be inconsistent with market efficiency. Note that we assume the same transaction costs for each of the 150 largest stocks in our sample, while it could be the case that, e.g., momentum stocks are more expensive than the average stock (see, e.g., Korajczyk and Sadka (2004) and Lesmond, Schill, and Zhou (2004)). Since we do not have transactions costs data on individual stocks, we cannot undertake such analysis in this paper. We leave this as a topic for further research. On the other hand, our assumption on transaction costs is conservative. Transaction costs in reality might be lower, leading to higher net returns for momentum investors in frontier emerging markets.

\section{Risk-based explanations}

In this section we analyze whether exposure to global risk factors can explain the existence of the factor anomalies and whether the factors are prone to extreme downside risk. We conclude this section with an analysis of the return factors in the recent crisis period.

\subsection{Exposure to global risk factors}

In the previous sections we showed that value and momentum effects, and to a lesser extent the local size effect, are present in frontier emerging markets. However, to which extent do the results serve as out-of-sample evidence of these effects? In this section we address the question of whether our findings are independent of the 
existence of the effects in emerging and developed markets. In other words, we investigate to which extent the results are driven by well-known global risk factors.

A first analysis to get insight in the independence of our results is by examining the correlations between the strategies across frontier, emerging and developed markets. Miles (2005), Speidell and Krohne (2007), and Berger, Pukthuanthong, and Yang (2011) indicate that investors may benefit from the diversification opportunities of frontier equity market returns. They consider frontier markets as a group at the index level or at the country index level. We want to go one step further in our analysis and examine whether investment strategies in frontier markets correlate with the same strategies in developed and emerging equity markets. If the correlation is low, this might be an indication that value, momentum and size strategies do not have common components across markets.

In order to use international risk factors we need to construct international investment portfolios. The global developed markets size, value, and momentum returns are constructed as follows. Using a survivorship-bias free data set of stock constituents of the FTSE World index, we form monthly rankings according to local size (measured by market capitalization relative to the stocks within their own country), value, and momentum. We form equally-weighted portfolios and calculate US dollar hedged returns using a 12-month holding period. For the emerging markets factor returns we use the same methodology based on all stocks in the S\&P/IFCI Emerging Markets index. Returns of these strategies are measured in US dollars. ${ }^{32}$

\section{$<<$ insert Table 5 about here $>>$}

Table 5 contains the correlations of returns for the equally-weighted market index and the value, momentum, and size factors between the frontier, emerging and developed markets. The correlations are estimated over the full sample period 1997-2008 and two sub-sample periods from 1997-2002 and 2003-2008. Based on the first row of Table 5, we observe that the correlation between the frontier market index and the

\footnotetext{
${ }^{32}$ Hedging emerging markets currencies for the entire index for our entire sample period is virtually impossible because of a lack of sufficiently liquid instruments for some emerging currencies, especially in the beginning of our sample period.
} 
emerging and developed market indexes over the entire sample period is moderately positive (0.48 and 0.50 respectively), confirming the other studies stating that diversification benefits may be obtained from investing in frontier markets. The subsample analysis suggests that recently the correlation has increased, although this could be due to the financial crisis in the second half of 2008 in which all risky asset classes were highly correlated.

A different picture emerges when looking at the correlation of Top-Minus-Index investment strategy returns. Strikingly, none of the correlations with the frontier market investment strategies on the full sample exceed 0.2 , with the average correlation below 0.10 . As an example, the correlation of the 6-month momentum strategy between frontier markets and emerging markets is 0.03 and between frontier and developed markets is 0.08 . Furthermore, we do not find higher correlations between frontier and emerging markets than between frontier and developed markets. In the most recent sub-sample, correlations of the value factors between frontier and emerging markets slightly increased, but are still low with an average below 0.2.

These preliminary results indicate that the return factors in frontier markets seem to be independent of the existence of the effects in emerging and developed markets. Additionally, our results support findings of Griffin, Ji, and Martin (2003, 2005), Naranjo and Porter (2007), and Asness, Moskowitz, and Pedersen (2009), who suggest that investors may benefit from combining the same strategies in different (non-frontier) countries, as the returns from these strategies are far from perfectly positively correlated.

We continue by investigating whether the mean-variance efficient frontier of a portfolio invested in developed equity factor portfolios can be expanded by including investment strategies from frontier markets. In an unreported analysis, we find that when the frontier markets index is used as the new asset and emerging and developed markets indexes are used as the two base assets that the mean-variance efficient frontier is significantly expanded. We take our mean-variance spanning analysis one step further by testing whether the frontier market factor returns can expand the meanvariance frontier for investors in the same factors in developed and emerging markets. This is illustrated by Figure 2, in which the average return and volatility risk of the 
four international developed markets Carhart (1997) benchmark assets (market, value, size, and momentum) are displayed, as well as the dashed line that represents the mean-variance frontier based on these assets. The square indicates the $\mathrm{B} / \mathrm{M}$ strategy in frontier markets. The optimal benchmark portfolio scaled to sum to $100 \%$ consists of $17 \%$ in the entire market, $-1 \%$ in the size strategy, $41 \%$ in the value strategy and $44 \%$ in the momentum strategy. This strategy is shown on the mean-variance frontier with a triangle at a risk of $1.6 \%$ per month. In case the $\mathrm{B} / \mathrm{M}$ strategy based on frontier markets is added to the investment opportunity set, the mean-variance frontier expands with the optimal weight to this new asset class of $31 \%$. This portfolio is also shown on the mean-variance frontier.

$$
<\text { insert Figure } 2 \text { about here }>>
$$

Whether this portfolio weight of $31 \%$ is also significantly different from zero from a statistical point of view can be tested using mean-variance spanning tests; see De Roon and Nijman (2001) for an overview of interpretations of mean-variance spanning tests. They also indicate that tests for differences in Sharpe ratios of these two efficient portfolios, for example using the Jobson and Korkie (1981) test, is closely related to using alphas from regression-based mean-variance spanning tests. Sharpe ratios can be used to determine whether one portfolio is to be preferred over another, whereas alpha answers the question whether investors can improve the efficiency of their portfolio by investing in the new asset. In case the optimal portfolio weight of the new asset would be zero, the mean-variance frontiers would coincide, the alpha would be zero, and the Sharpe ratios of both portfolios would be the same.

A more direct analysis to assess the influence of global components would be to run a multiple regression of the frontier market return factors on their global counterparts. This approach is closely related to a formal mean-variance spanning test; see Huberman and Kandel (1987). For that purpose we estimate the following regression equation:

$$
R_{T M I, t}^{e}=\alpha+\beta_{M} R_{M, t}^{e}+\beta_{S M B} R_{S M B, t}^{e}+\beta_{H M L} R_{H M L, t}^{e}+\beta_{U M D} R_{U M D, t}^{e}+\varepsilon_{t}
$$


with SMB the local size factor, HML the value factor measured by the book-tomarket ratio, and UMD the 6-month momentum factor. In line with the literature, we use Top minus Bottom portfolio returns for the developed and emerging factors. These are essentially the four factors from Carhart (1997). An alpha statistically different from zero implies that the excess returns in frontier markets cannot be explained by global risk factors and hence these frontier market return factors are independent of existing effects in other markets.

The estimation results of Equation (1) are displayed in Table 6. Panel A contains the estimates for global developed risk factors and Panel B for global emerging risk factors. ${ }^{33}$ The positive alphas reported in Panel A and Panel B are similar to the previously reported excess returns as shown in the first two columns and are statistically significantly different from zero.

\section{$<<$ insert Table 6 about here $>>$}

For example, the E/P strategy has a statistically significant alpha of $1.23 \%$ and $1.26 \%$ per month relative to respectively the developed and emerging risk factors. Corresponding t-values are 5.69 and 5.28, respectively. The excess return of the TMI strategy reported before is $1.26 \%$, as indicated in the first column. For the 6-month momentum strategy the alpha is $0.75 \%$ (t-value 4.26) when adjusted for developed markets and $0.76 \%$ (t-value 3.73) when adjusted for emerging markets risk factors compared to a TMI excess return of $0.77 \%$ per month. We find similar results for the local size factor where the alpha is $0.52 \%$ ( $\mathrm{t}$-value of 3.03 ) when adjusted for developed markets and $0.50 \%$ (t-value is 2.93) when adjusted for emerging markets risk factors. These results reinforce our earlier results that correlations between return factors in frontier markets, developed and emerging markets are generally low. ${ }^{34}$ Our analysis in Table 6 suggests that global risk factors cannot explain the excess returns in frontier markets. Our results are in line with the findings by Van der Hart, De Zwart, and Van Dijk (2005), who claim that value and momentum investment

\footnotetext{
${ }^{33}$ We have also analyzed US-based factors from the online data library of Kenneth French. The results are qualitatively the same, see Appendix C. We also show in Appendix $C$ that our results cannot be explained by the traded liquidity factor of Pastor and Stambaugh (2003) and non-traded liquidity factors of Sadka (2006).

${ }^{34}$ The conclusions do not change when we regress net excess returns of our investment strategies on the same risk factors, see Appendix D.
} 
strategies in emerging markets are not exposed to global risk factors. Of course, our results do not rule out that local risk factors can explain these effects. Unfortunately, limited data availability in these markets (for example on earnings or earnings estimates) does not allow us to disentangle local risk factors from behavioral explanations. We think this is a fruitful area for further research once more reliable data becomes available.

\subsection{Downside risk}

Although the descriptive statistics in Table 1 show that the volatility of the aggregated frontier markets is not high, the factor returns might have more extreme observations in the sense of higher skewness and kurtosis than can be expected based on normality. Therefore, we calculate in addition to the average and standard deviation of portfolio returns also the skewness and kurtosis. ${ }^{35} \mathrm{We}$ display these results in Table 7 . The positive values show that excess kurtosis often exceeds the prediction derived from normally distributed returns. This indicates that there are more extreme returns than mean and variance can capture. Interestingly, the skewness for most of the factor returns (apart from 6-month momentum) is also positive, indicating that the deviation from normality is due to exceptionally large upward potential instead of increased downside risk.

\section{< insert Table 7 about here >>}

In order to examine downside risk in more detail, we compare empirical estimates of downside risk to the theoretical equivalent under the assumption of normality. More precisely, we calculate the $1 \%$ and $2.5 \%$ and $97.5 \%$ and $99 \%$ percentiles of the monthly returns and compare these to the parametric percentile derived from the normal distribution with the same mean and variance as our strategies. These results confirm our prediction based on the positive skewness and kurtosis, in the sense that it is the upward potential instead of the downside risk that causes deviations from normality. Based on the $1 \%$ percentile, we find that most strategies exhibit comparable or lower downside risk than would be expected based on a normal

\footnotetext{
${ }^{35} \mathrm{We}$ also computed the Jarque-Bera test on the normality of portfolio returns. This test is based on the skewness and kurtosis. We frequently reject normality, but this is not so much due to increased downside risk, but due to higher upside. This is why we empirically determine the downside risk of our strategies and compare these to the risk measures following from a normal distribution.
} 
distribution. Only the 12-month momentum strategy exhibits substantially higher downside risk, as the empirical $1 \%$ percentile is $-5.19 \%$ versus $-4.67 \%$ based on the $1 \%$ theoretical percentile. Based on the $2.5 \%$ percentile we find that all strategies exhibit a lower downside risk than expected based on a normal distribution. Additionally, we find that many factor returns exhibit empirically higher upside potential that would be expected based on a normal distribution. For example, the B/M strategy's $99 \%$ percentile is $10.12 \%$, whereas based on the normal distribution this would be $7.52 \%$. In case the upside is less, the differences are small with the expected upside. Hence, we deem it unlikely that downside risk can explain the empirical results we document.

\subsection{Results for the crisis period 2008-2011}

The turmoil in financial markets after our research period 1997 to 2008 is an interesting out-of-sample period to test whether the return factors we document are still present in our sample of frontier emerging markets. For the recent crisis period ranging from December 2008 to December 2011 (37 months), we make use of the frontier market data sources to form portfolios in exactly the same fashion as done in our previous analyses. ${ }^{36}$ In November 2008, the S\&P Frontier BMI experienced major changes and has expanded from 24 to 35 countries, including the five Gulf Cooperative Council (GCC) country members. As our data provider is not able to cope with these GCC countries, because the trading days also include (Western) weekends, we focus in this sub-section on the main analyses conducted on the dataset excluding these countries and use our original dataset for all further analyses.

The out-of-sample results are presented in Table 8. Panel A shows the excess returns of the return factors over this period. We see that value and size effects have been strong over the past 37 months in the recent crisis period. Similar to developed and emerging markets, momentum effects have not been present in this period filled with turmoil. This is due to the market reversal, from down in 2008 to up in 2009 and down again in 2011. As indicated by Blitz, Huij, and Martens (2011), momentum strategies exhibit time-varying risk factors and hence are likely to underperform in

\footnotetext{
${ }^{36}$ We verify that the data is of high quality by calculating the index return from individual stock returns and market capitalisations and comparing the index return with the return published by S\&P on the index.
} 
markets with strong reversals. Note that the returns of the momentum strategies in frontier markets are still economically and statistically significant over the whole sample period from 1997 until 2011. Our results once more indicate that value and momentum show different return patterns implying that combining both types of strategies leads to diversification benefits.

\section{$<<$ insert Table 8 here $>>$}

In Panel B of Table 8, we also display the correlation between the factor returns in developed, emerging, and frontier markets for the out-of-sample period. We see that the correlation between developed and emerging markets has remained high at 0.90 at the market level, while frontier markets' correlation with emerging and developed markets has increased to 0.76 and 0.78 . For most other factors, the correlation of frontier markets with developed and emerging markets has increased to around 0.5. This indicates that the diversification benefits that we observed in our sample have become smaller in the out-of-sample period. Nevertheless, the correlation with frontier markets factors remains substantially below the correlation between developed and emerging markets, indicating that investors could still reap diversification benefits by investing in the frontier market factors, although less than before.

\section{Conclusions}

The new emerging equity markets, the so-called frontier emerging markets, are attracting increased attention from foreign investors. Research on these frontier markets is scarce and mostly conducted using the frontier market as a whole or at the country level. In this paper, we dig one step deeper and analyze the cross-section of individual stock returns. Our research on individual stocks in frontier emerging markets makes use of a unique high-quality and survivorship-bias free dataset. The use of individual stock characteristics data allows us to investigate the added value of investment strategies relative to strategies that only use aggregated data at the country level. We use data from more than 1,400 stocks from 24 frontier markets over a 12year period from 1997 to 2008. This previously untapped data source provides 
excellent opportunities for out-of-sample research related to investment strategies that were previously analyzed in developed and emerging markets.

Our empirical results indicate that portfolios based on value and momentum in frontier markets generate economically and statistically significant excess returns of about 5 to $15 \%$ per annum. The magnitude of these excess returns is at least as large as those found before in developed and emerging markets. We also find that there is a local size effect in frontier markets. These are striking empirical observations, as integration of frontier markets with developed and emerging markets is generally low. Our results are valuable out-of-sample evidence of the cross-section of stock returns previously documented in developed markets. These results are robust as they still hold after performing a battery of robustness analyses, such as an analysis by geographical region and financial liberalization.

Investors who are interested to capture the value and momentum effect might be concerned with the transaction costs involved, as liquidity is typically lower than for more developed equity markets. We analyse the after transaction costs returns of value and momentum strategies using conservative estimates from Marshall et al. (2011) on a liquid sample of the largest 150 frontier market stocks including a onemonth skip between ranking and implementation of the stocks in portfolio. Our results indicate that net excess returns are approximately $7 \%$ per annum for value and momentum strategies. These excess returns are both economically and statistically significant and therefore do not explain the existence of these factor returns.

We additionally investigate whether the factor returns in frontier markets can be explained by risk. First, our results are not driven by frontier market, country- or region exposures, as our results still hold when correcting for these exposures. Second, our results cannot be explained by exposure to global risk factors, such as market, value, momentum and size. Third, it is unlikely that downside risk can explain the empirical results. Hence, we believe it is unlikely that transaction costs or risk can explain the strong factor returns. Although we cannot rule out that exposures to other global risk factors or local risk might explain the returns of the strategies, future research could investigate to which extent behavioural biases might explain the value, momentum and size effect in frontier markets. 


\section{References}

Asness, C.S., Moskowitz, T.J., and Pedersen, L.H., 2009, "Value and momentum everywhere", working paper available on SSRN at http://ssrn.com/abstract=1363476

Baker, M., Bradley, B., and Wurgler, J., 2011, "Benchmarks as Limits to Arbitrage: Understanding the Low-Volatility Anomaly", Financial Analysts Journal 67(1), pp. 40-54.

Banz, R.W., 1981, "The relationship between return and market value of common stocks", Journal of Financial Economics 9, pp. 3-18.

Barberis, N., Shleifer, A., Vishny, R.W., 1998. "A model of investor sentiment”, Journal of Financial Economics 49, pp.307- 343

Barry, C.B., Goldreyer, E., Lockwood, L., Rodriguez, M., 2002, "Robustness of size and value effects in emerging equity markets,1985-2000", Emerging Markets Review 3, pp. 1-30.

Bekaert, G., and Harvey, C.R., 1995, "Time-varying world market integration", Journal of Finance 50, pp. 403-444.

Bekaert, G., and Harvey, C.R., 2000, "Foreign speculators and emerging equity markets", Journal of Finance 55, pp. 565-614.

Bekaert, G., and Harvey, C.R., 2003, "Emerging markets finance", Journal of Empirical Finance 10(1-2), pp. 3-56.

Bekaert, G., Harvey, C.R., and Lundblad, C., 2007, "Liquidity and expected returns: Evidence from Emerging Markets", Review of Financial Studies 20, pp. 1783-1831.

Berger, D., Pukthuanthong, K., and Yang, J., 2011, "International diversification with frontier markets“, Journal of Financial Economics 101(1), 227-242.

Bhojraj, S., and Swaminathan, B., 2006, "Macromomentum: Returns predictability in international equity indices", Journal of Business 79(1), pp. 429-451.

Black, F., 1972, "Capital Market Equilibrium with Restricted Borrowing." Journal of Business, 45, pp. 444-455.

Black, F., Jensen, M.C., and Scholes, M., 1972, "The Capital Asset Pricing Model: Some Empirical Tests" In Studies in the Theory of Capital Markets. Praeger, New York: pp. 79-121.

Blitz, D.C., Huij, J., and Martens, M., 2011, "Residual momentum", Journal of Empirical Finance 18(3), pp. 506-521.

Blitz, D.C., and Van Vliet, P., 2007, "The volatility effect: Lower risk without lower return", Journal of Portfolio Management 34(1), pp. 102-113.

Blitz, D.C., Van Vliet, P., and Pang, J., 2012, "The volatility effect in emerging markets", working paper available at SSRN: http://ssrn.com/abstract=2050863

Carhart, M., 1997, “On persistence in mutual fund returns”, Journal of Finance 52(1), pp. 5782.

Chan, K., Hameed, A., and Tong, W., 2000, "Profitability of momentum strategies in the international equity markets", Journal of Financial and Quantitative Analysis 35(2), pp. 153172.

Chui, A.C.W., Titman, S., and Wei, K.C.J., 2010, "Individualism and momentum around the world”, Journal of Finance, 65(1), pp. 361-392.

Conrad, J., and Kaul, G., 1998, "An anatomy of trading strategies", Review of Financial Studies 11, pp. 489-519. 
Daniel, K., Hirshleifer, D., Subrahmanyam, A., 1998, "Investor psychology and security market under- and overreactions", Journal of Finance 53, pp. 1839-1885.

De Bondt, W.F.M., and Thaler, R.H., 1985, “Does the stock market overreact?”, Journal of Finance 40, 793-805.

De Groot, W., J. Huij, and Zhou, W., 2011, “Another look at trading costs and short-term reversal profits", Journal of Banking and Finance, forthcoming.

De Roon, F.A., and Nijman, Th.E., 2001, "Testing for mean-variance spanning: A survey", Journal of Empirical Finance 8(2), pp. 111-155.

De Roon, F.A., and Nijman, Th.E., and Werker, 2001, "Testing for Mean-Variance spanning with short sales constraints and transaction costs: The case of emerging markets", Journal of Finance 56(2), pp. 721-742.

Dreher, A., 2006, "Does Globalization Affect Growth? Evidence from a new Index of Globalization", Applied Economics 38(10), pp. 1091-1110.

Erb, C.B., Harvey, C.R., and Viskanta, T., 1996, "Expected returns and volatility in 135 countries", Journal of Portfolio Management 22, pp. 46-58.

Falkenstein, E., 2009, Finding alpha: the search for alpha when risk and return break down, John Wiley \& Sons: Hoboken, New Jersey.

Fama, E.F., and French, K.R., 1992, "The cross-section of expected stock returns", Journal of Finance 47, 427-465.

Fama, E.F., and French, K.R., 1993, "Common risk factors in the returns on stocks and bonds", Journal of Financial Economics 33, pp. 3-56.

Fama, E.F., and French, K.R., 1998, "Value versus growth: the international evidence", Journal of Finance 53(6), pp. 1975-2000.

Girard, E., and Sinha, A.K., 2008, "Risk and return in the next frontier", Journal of Emerging Markets Finance 7, pp. 43-80.

Goetzmann, W., Li, L., and Rouwenhorst, K.G, 2005, "Long-term global market correlations", Journal of Business 78(1), pp. 1-38.

Griffin, J.M., Ji, X., and Martin, S.J., 2003, "Momentum investing and business cycle risk: evidence from pole to pole", Journal of Finance 58(6), pp. 2515-2547.

Griffin, J.M., Ji, X., and Martin, S.J., 2005, "Global momentum strategies: A portfolio perspective", Journal of Portfolio Management 31(2), pp. 23-39.

Griffin, J.M., Kelly, P.J., and Nadari, F., 2010, "Do Market Efficiency Measures Yield Correct Inferences? A Comparison of Developed and Emerging Markets", Review of Financial Studies 23(8), pp. 3225-3277.

Heston, S.L., Rouwenhorst, K.G., Wessels, R.E., 1999, "The role of beta and size in the crosssection of European stock returns", European Financial Management 5, pp. 9-27.

Hofstede, G., 2001, Culture's Consequences: Comparing Values, Behaviors, Institutions, and Organizations across Nations, 2nd edition (Sage Publication: Beverly Hills, CA).

Houge, T., and Loughran, T., 2006, "Do investors capture the value premium?", Financial Management 35(2), pp. 5-19.

Hong, H., Stein, J.C., 1999, "A unified theory of underreaction, momentum trading, and overreaction in asset markets", Journal of Finance 54, pp. 2143- 2184.

Huberman, G., and Kandel, S., "Mean-variance spanning", Journal of Finance 42, pp. 837888. 
Jegadeesh, N., 1990. "Evidence of Predictable Behavior of Security Returns", Journal of Finance. 45(3), pp. 881-98.

Jegadeesh, N., and Titman, S., 1993, "Returns to buying winners and selling losers: Implications for stock market efficiency", Journal of Finance 48, pp. 65-91.

Jegadeesh, N., and Titman, S., 2001, "Profitability of momentum strategies: an evaluation of alternative explanations", Journal of Finance 56(2), pp. 699-720.

Jobson, J.D., and Korkie, B., 1981, "Performance hypothesis testing with the Sharpe and Treynor measures", Journal of Finance 36, pp. 888-908.

Keim, D.B., Madhavan, A., 1997, "Transaction costs and investment style: An interexchange analysis of institutional equity trades", Journal of Financial Economics 46, pp. 265-292.

Khandani, A.E., and Lo, A., 2007, "What happened to the Quants in 2007?", Journal of Investment Management 5, pp. 5-54.

Korajczyk, R.A., and Sadka, R., 2004, "Are momentum profits robust to trading costs?", Journal of Finance 59(3), pp. 1039-1082.

Marshall, B.R., Nguyen, N.H., and Visaltanachoti, N., 2011, "Frontier market diversification and transactions costs", working paper available on SSRN: http://ssrn.com/abstract=1942592

Miles, W., 2005, "Do frontier equity markets exhibit common trends and still provide diversification opportunities?", International Economic Journal 19(3), pp. 473 - 482.

Lakonishok, J., Shleifer, A. and Vishny, R.W., 1994, "Contrarian investment, extrapolation, and risk", Journal of Finance 49, 1541-1578.

Lesmond, D.A., 2005, "Liquidity of emerging markets", Journal of Financial Eonomics 77(2), pp. 411-452.

Lesmond, D.A., Schill, M.J., and Zhou, C., 2004, "The illusionary nature of momentum profits", Journal of Financial Economics 71(2), pp. 349-380.

Lo, A.W., and MacKinlay, A.C., 1990, "Data-snooping biases in tests of financial asset pricing models", Review of Financial Studies 3(3), pp. 431-467.

Naranjo, A., and Porter, B., 2007, "Including emerging markets in international momentum investment strategies", Emerging Markets Review 8, pp. 147-166.

Newey, W.K., and West, K.D., 1987, "A simple, positive semi-definite, heteroskedasticity and autocorrelation consistent covariance matrix", Econometrica 55(3), pp. 703-708.

Pastor, L., and Stambaugh, R.F., 2003, "Liquidity risk and expected stock returns", Journal of Political Economy 111, pp. 642-685.

Rouwenhorst, K.G., 1998, "International Momentum Strategies", Journal of Finance 53(1), 267-284.

Rouwenhorst, K.G., 1999, "Local return factors and turnover in emerging stock markets", Journal of Finance 54, 1439-1464.

Sadka, R., 2006, "Momentum and post-earnings-announcement drift anomalies: The role of liquidity risk", Journal of Financial Economics 80, pp. 309-349.

Shefrin, H., and Statman, M., 2000,. "Behavioral Portfolio Theory" Journal of Financial and Quantitative Analysis, 35(2), pp. 127-151.

Shumway, T., 1997, "The Delisting Bias in CRSP Data", Journal of Finance, 52, 327 - 340.

Speidell, L.S., and Krohne, A., 2007, "The case for frontier markets", Journal of Investing 16(3), pp. 12-22. 
Speidell, L.S., 2009, "Investing in the unknown and the unknowable - Behavioral finance in frontier markets", Journal of Behavioral Finance 10(1), 1-8.

Van Binsbergen, J., Brandt, M., and Koijen, R., 2008, "Optimal decentralized investment management”, Journal of Finance 63(4), pp. 1849-1895.

Van der Hart, J., Slagter, E., and Van Dijk, D.J., 2003, "Stock selection strategies in emerging markets", Journal of Empirical Finance 10(1-2), pp. 105-132.

Van der Hart, J., De Zwart, G.J., and Van Dijk, D.J., 2005, "The success of stock selection strategies in emerging markets: Is it risk or behavioral bias?", Emerging Markets Review 6(3), pp. 238-262.

Van Dijk, M.A., 2011, "Is size dead? A review of the size effect in equity returns", Journal of Banking and Finance, forthcoming. 


\section{Table 1: Summary statistics of frontier markets firms}

The table gives for each country the region classification, the inclusion date in the S\&P Frontier BMI, the (end of month) index weights at the inclusion date and in October 2008, the number of firms at the inclusion date and October 2008, the average monthly return and the standard deviation of the returns of the equally-weighted index of the sample firms over the period since the inclusion date until November 2008, both in local currency (LC) and US dollars (USD). The next four columns show the summary statistics median firm size, median book-to-market ratio $(B / M)$, median earnings-to-price ratio $(E / P)$, and median dividend yield $(D / P)$ of the sample firms. Size is measured as the market capitalization of the firms in millions of US dollars. The medians are computed per month across firms, and the table reports the time series average of these monthly medians. The turnover ratio is a country average of the value of stock trades divided by the market capitalization in the inclusion year and 2008. In addition, the average of the statistics is displayed. The bottom rows show statistics for the equally-weighted (EW) and value-weighted (VW) index and the difference between the two. In the last row, the number between brackets is the t-value corresponding to the hypothesis that the average returns of the EW and VW index are the same.

\begin{tabular}{|c|c|c|c|c|c|c|c|c|c|c|c|c|c|c|c|c|}
\hline \multirow[b]{2}{*}{ Country } & \multirow[b]{2}{*}{ Region } & \multirow{2}{*}{$\begin{array}{c}\text { Inclusion } \\
\text { date }\end{array}$} & \multicolumn{2}{|c|}{ Index weights (\%) } & \multicolumn{2}{|c|}{ Number of firms } & \multicolumn{2}{|c|}{ LC Return (\%) } & \multicolumn{2}{|c|}{ USD Return (\%) } & \multirow{2}{*}{$\begin{array}{c}\text { Median } \\
\text { size }\end{array}$} & \multirow{2}{*}{$\begin{array}{c}\text { Median } \\
\text { B/M }\end{array}$} & \multirow{2}{*}{$\begin{array}{l}\text { Median } \\
\mathrm{E} / \mathrm{P}(\%)\end{array}$} & \multirow{2}{*}{$\begin{array}{l}\text { Median } \\
\text { D/P (\%) }\end{array}$} & \multicolumn{2}{|c|}{ Turnover ratio } \\
\hline & & & Begin & Oct-08 & Begin & Oct-08 & Mean & Std.Dev & Mean & Std.Dev. & & & & & Begin & 2008 \\
\hline Bangladesh & Asia & Jan-97 & 19.1 & 4.7 & 46 & 25 & 0.5 & 7.6 & 0.2 & 7.8 & 17 & 0.8 & 8.8 & 3.3 & 12.6 & 137.3 \\
\hline Botswana & Africa & Jan-97 & 1.6 & 2.4 & 7 & 6 & 2.6 & 5.0 & 2.1 & 5.8 & 102 & 0.2 & 8.2 & 5.6 & 12.6 & 3.1 \\
\hline Bulgaria & Europe & Jan-97 & 0.03 & 0.9 & 12 & 11 & 1.4 & 8.8 & 1.4 & 11.2 & 19 & 1.6 & 9.3 & 0.2 & 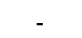 & 10.8 \\
\hline Côte d'Ivoire & Africa & Jan-97 & 4.2 & 5.0 & 7 & 13 & 1.3 & 4.9 & 1.4 & 6.0 & 46 & 0.7 & 11.7 & 5.6 & 2.2 & 4.1 \\
\hline Croatia & Europe & Jan-98 & 9.1 & 5.4 & 8 & 15 & 1.6 & 9.0 & 1.7 & 9.3 & 87 & 1.5 & 9.9 & 0.9 & 2.8 & 7.4 \\
\hline Ecuador & America & Jan-97 & 8.7 & 3.2 & 11 & 6 & 1.7 & 5.2 & 0.4 & 7.0 & 86 & 0.9 & 10.6 & 4.4 & 8.7 & 3.6 \\
\hline Estonia & Europe & Jan-98 & 5.4 & 1.0 & 12 & 7 & 0.2 & 9.0 & 0.6 & 9.2 & 45 & 0.6 & 8.1 & 2.0 & 113.8 & 19.6 \\
\hline Ghana & Africa & Jan-97 & 8.0 & 1.4 & 7 & 10 & 3.2 & 6.7 & 1.9 & 7.4 & 30 & 0.4 & 17.7 & 3.5 & 3.7 & 5.2 \\
\hline Jamaica & America & Jan-97 & 11.3 & 3.5 & 22 & 15 & 2.2 & 8.4 & 1.6 & 8.3 & 45 & 0.9 & 12.8 & 3.4 & 3.7 & 3.6 \\
\hline Kazakhstan & Europe & Dec-07 & 17.9 & 13.8 & 13 & 13 & -2.0 & 19.8 & -2.0 & 19.7 & 600 & 0.5 & 10.1 & - & 20.9 & 9.5 \\
\hline Kenya & Africa & Jan-97 & 10.9 & 4.8 & 16 & 20 & 1.8 & 7.0 & 1.6 & 7.9 & 46 & 0.5 & 8.5 & 4.4 & 5.8 & 11.8 \\
\hline Latvia & Europe & Jan-98 & 1.3 & 0.2 & 11 & 9 & 0.1 & 8.9 & 0.2 & 9.2 & 7 & 2.8 & 10.0 & 0.3 & 23.6 & 1.8 \\
\hline Lebanon & Asia & Sep-99 & 8.4 & 11.4 & 5 & 5 & 1.3 & 7.8 & 1.3 & 7.8 & 331 & 1.0 & 2.7 & 0.9 & 4.2 & 6.9 \\
\hline Lithuania & Europe & Jan-97 & 2.2 & 0.9 & 31 & 15 & 0.6 & 6.9 & 0.9 & 7.7 & 23 & 1.1 & 9.5 & 0.7 & 18.0 & 7.1 \\
\hline Mauritius & Africa & Jan-97 & 6.6 & 3.9 & 13 & 9 & 1.0 & 4.3 & 0.7 & 4.8 & 45 & 0.9 & 11.2 & 4.8 & 8.1 & 8.9 \\
\hline Namibia & Africa & Sep-99 & 2.1 & 0.3 & 9 & 4 & 1.4 & 6.5 & 1.2 & 8.9 & 21 & 0.6 & 14.4 & 3.1 & 4.0 & 2.8 \\
\hline Panama & America & Dec-07 & 2.4 & 5.6 & 11 & 11 & -2.7 & 6.7 & -0.1 & 1.5 & 77 & 0.6 & 7.2 & - & 2.0 & 4.0 \\
\hline Romania & Europe & Jan-98 & 3.8 & 4.3 & 33 & 15 & 1.1 & 9.7 & 0.3 & 10.8 & 36 & 0.8 & 6.1 & 0.2 & 72.6 & 11.3 \\
\hline Slovakia & Europe & Nov-04 & 2.1 & 0.7 & 4 & 6 & 2.1 & 5.3 & 2.7 & 7.2 & 40 & 2.4 & 10.3 & 2.8 & 18.2 & 0.4 \\
\hline Slovenia & Europe & Jan-97 & 5.2 & 10.2 & 10 & 10 & 1.0 & 5.6 & 0.9 & 6.5 & 166 & 1.1 & 6.2 & 1.7 & 30.7 & 6.9 \\
\hline Trinidad \& Tobago & America & Jan-97 & 7.8 & 6.5 & 11 & 6 & 1.3 & 4.3 & 1.3 & 4.4 & 237 & 0.3 & 6.5 & 2.3 & 5.9 & 2.6 \\
\hline Tunisia & Africa & Jan-97 & 14.4 & 3.5 & 11 & 17 & 0.6 & 4.0 & 0.4 & 4.4 & 57 & 0.7 & 8.0 & 4.2 & 7.9 & 25.5 \\
\hline Ukraine & Europe & Jan-98 & 4.2 & 2.3 & 17 & 18 & 3.9 & 17.9 & 3.1 & 18.3 & 70 & 2.3 & 12.4 & 0.0 & 4.4 & 3.7 \\
\hline Vietnam & Asia & Dec-06 & 9.4 & 4.0 & 18 & 24 & -2.3 & 17.5 & -2.4 & 17.9 & 107 & 0.1 & 2.7 & 0.0 & 22.4 & 44.8 \\
\hline Average & - & - & 6.9 & 4.2 & 14 & 12 & 1.0 & 8.2 & 0.9 & 8.7 & 98 & 1.0 & 9.3 & 2.5 & 17.8 & 14.3 \\
\hline EW Index & - & Jan-97 & 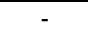 & 100 & & 290 & 1.4 & 4.0 & 0.8 & 4.2 & - & & - & - & - & - \\
\hline VW Index & - & Jan-97 & - & 100 & - & 290 & 1.1 & 3.9 & 0.8 & 4.1 & - & - & - & - & - & - \\
\hline EW minus VW & - & - & - & - & - & - & $0.3(1.2)$ & - & $0.1(0.4)$ & - & - & - & - & - & - & - \\
\hline
\end{tabular}




\section{Table 2: Excess returns of portfolios sorted on value, momentum, size, and low-risk characteristics}

At the end of each month between January 1997 and October 2008, all stocks in the S\&P Frontier BMI for which the necessary information is available are ranked in descending order (apart from size and low-risk) according to their characteristics. B/M is the book-to-market ratio; E/P is the earnings-to-price ratio; D/P is the dividend-toprice ratio. MOM3, MOM6 and MOM12 are the past returns with formation periods of 3, 6, and 12 months. Size is the market capitalization of a stock and is ranked in ascending order, Beta is the 36-month historical covariance with the index return, and Volatility is the 36-month historical standard deviation of individual stock returns, both ranked in ascending order. The holding period is 12 months. The columns 'Return' contain the average monthly percentage excess returns of the equally-weighted top $20 \%$ portfolio minus the average returns of equally-weighted universe (index), except for rows with "top-minus-bottom" and "index-minus-bottom". The corresponding t-values are presented next to the 'Return' columns. T-values are corrected for heteroskedasticity and autocorrelation using Newey and West (1987). In panel A, the row "top-minusbottom" contains excess returns of the top $20 \%$ versus bottom $20 \%$ portfolios. The row "index-minus-bottom" contains returns of the equally-weighted average of the universe minus the bottom $20 \%$ portfolio. The "EW and VW market risk adjusted" rows contains the alphas relative to a single-factor model with the equally-weighted (EW) and value-weighted (VW) frontier market index as the risk factor. The region (country) neutral results have the same number of stocks from each region (country) in the topminus-index portfolios. Finally, the last row indicates the results for the countries with a low individualism score. In panel B, the sample is split in halves from the most and least liberalized countries according to three definitions of liberalization (Heritage Foundation (HF), ETH Zurich (KOF), and Fraser Institute (EFW)). The split is in such a way that at each point in time about half the stocks are in the sample that is most liberalized, and half that is least liberalized. Country neutrality is only applied to the size portfolio in panel B.

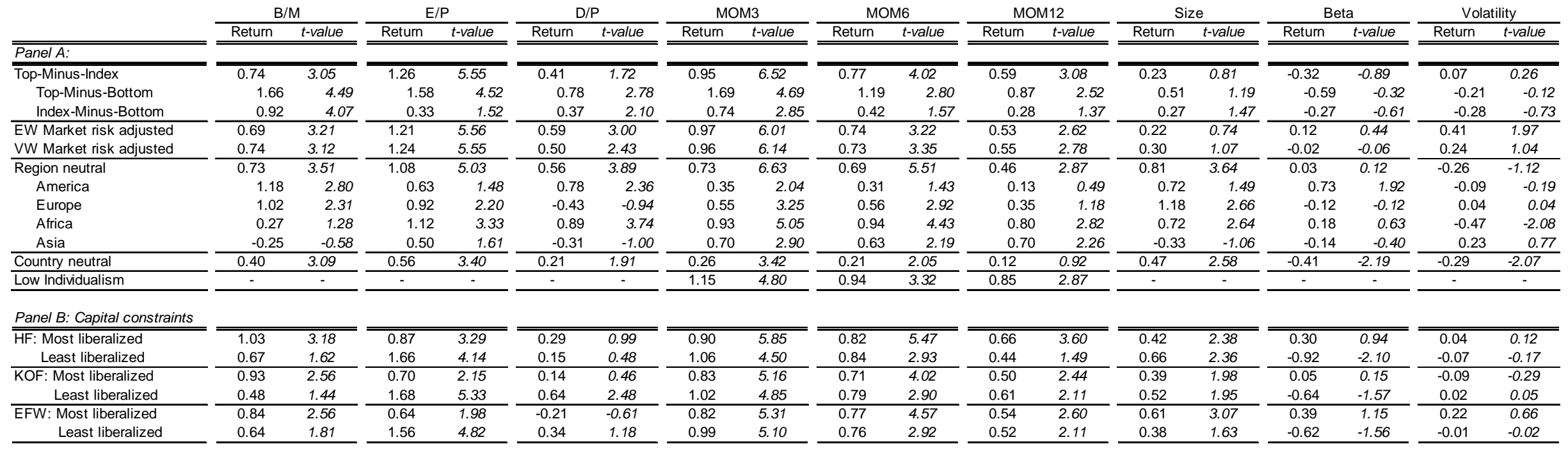


Table 3: Correlation between value, momentum, and size strategies in frontier markets

The table contains the correlations between the monthly top-minus-index excess returns of the value, momentum, and size strategies in frontier emerging markets. All portfolios are formed as described in Table 2 . Country neutrality is only applied to the size portfolio.

\begin{tabular}{|c|c|c|c|c|c|c|c|}
\hline & \multicolumn{3}{|c|}{ Value } & \multicolumn{3}{|c|}{ Momentum } & Size \\
\hline & $\mathrm{B} / \mathrm{M}$ & $E / P$ & $\mathrm{D} / \mathrm{P}$ & MOM3 & MOM6 & MOM12 & Size \\
\hline$B / M$ & 1 & 0.47 & -0.33 & 0.18 & -0.17 & -0.25 & 0.23 \\
\hline$E / P$ & & 1 & 0.00 & 0.20 & 0.03 & -0.21 & 0.01 \\
\hline$D / P$ & & & 1 & -0.18 & -0.12 & -0.09 & -0.26 \\
\hline MOM3 & & & & 1 & 0.51 & 0.35 & -0.03 \\
\hline MOM6 & & & & & 1 & 0.75 & -0.07 \\
\hline MOM12 & & & & & & 1 & -0.07 \\
\hline Size & & & & & & & 1 \\
\hline
\end{tabular}




\section{Table 4: Excess returns of value and momentum portfolios before and after trading costs}

The table reports gross and net excess returns of value and momentum portfolios. All portfolios are formed as described in Table 2, except that the sample only contains the largest 150 stocks in each month and one month is skipped between ranking and portfolio formation. The gross returns are the top-minus-index excess returns. The net returns are calculated as gross returns minus portfolio turnover multiplied by $2.5 \%$ single-trip trading costs. Two types of index returns are chosen to calculate the net excess portfolio returns. One is the gross index return, and another is the index return net of transaction costs caused by index turnover. Monthly single-trip portfolio turnovers are presented in percentages. The turnover caused by index changes is taken into account as part of portfolio turnover. Portfolios with holding periods of 12 months, 6 months, 18 months, and 24 months are reported, respectively.

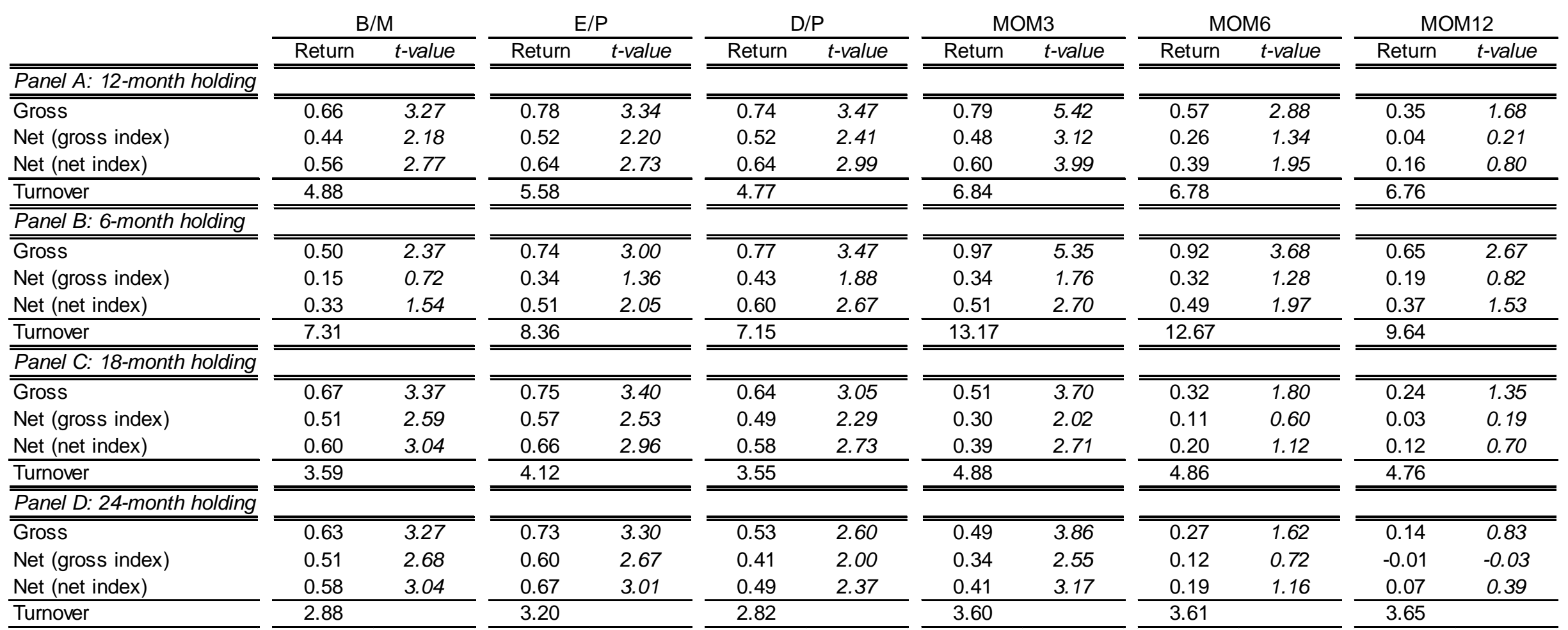


Table 5: Correlation between frontier, emerging, and developed market investment strategies

The first row contains the correlations between the equally-weighted market portfolios. The next rows contain the correlations of monthly excess returns of the value, momentum, and size top-minus-index portfolios between frontier markets (FM), emerging markets (EM) and developed markets (DM), for which we respectively use the S\&P Frontier BMI, S\&P/IFCI Emerging Markets and the FTSE World index. All portfolios are formed as described in Table 2. Country neutrality is only applied to the size portfolio. The row denoted by "average" contains the average correlation of the value and momentum strategies. The table contains correlations over the full sample period January 1997 to November 2008 and two sub-samples January 1997 to December 2002 and January 2003 to November 2008.

\begin{tabular}{|c|c|c|c|c|c|c|c|c|c|}
\hline & \multicolumn{3}{|c|}{ Full sample 1997-2008 } & \multicolumn{3}{|c|}{ First half $1997-2002$} & \multicolumn{3}{|c|}{ Second half $2003-2008$} \\
\hline & FM, EM & FM, DM & EM, DM & FM, EM & FM, DM & EM, DM & FM, EM & FM, DM & EM, DM \\
\hline Market & 0.48 & 0.50 & 0.82 & 0.04 & 0.05 & 0.75 & 0.81 & 0.80 & 0.91 \\
\hline $\mathrm{B} / \mathrm{M}$ & 0.09 & 0.06 & 0.46 & 0.09 & 0.05 & 0.50 & 0.10 & 0.10 & 0.22 \\
\hline$E / P$ & 0.01 & -0.05 & 0.27 & -0.05 & -0.06 & 0.30 & 0.16 & -0.03 & 0.17 \\
\hline $\mathrm{D} / \mathrm{P}$ & 0.14 & -0.15 & 0.12 & -0.03 & -0.19 & 0.18 & 0.32 & -0.13 & -0.03 \\
\hline Average value & 0.08 & -0.05 & 0.28 & 0.00 & -0.07 & 0.33 & 0.19 & -0.02 & 0.12 \\
\hline MOM3 & 0.05 & 0.20 & 0.32 & 0.08 & 0.28 & 0.23 & -0.01 & 0.10 & 0.47 \\
\hline MOM6 & 0.03 & 0.08 & 0.26 & 0.04 & 0.08 & 0.22 & 0.03 & 0.09 & 0.45 \\
\hline MOM12 & 0.07 & 0.00 & 0.32 & 0.06 & 0.01 & 0.30 & 0.08 & -0.03 & 0.46 \\
\hline Average momentum & 0.05 & 0.09 & 0.30 & 0.06 & 0.12 & 0.25 & 0.03 & 0.05 & 0.46 \\
\hline Size & 0.13 & 0.08 & 0.20 & 0.17 & 0.11 & 0.17 & 0.05 & 0.04 & 0.24 \\
\hline
\end{tabular}




\section{Table 6: Regressions of frontier markets excess returns on global risk factors}

The table presents coefficient estimates and t-values of the regression equation: $R_{T M I, t}^{e}=\alpha+\beta_{M} \cdot R_{M, t}^{e}+\beta_{S M B} \cdot R_{S M B, t}^{e}+\beta_{H M L} \cdot R_{H M L, t}^{e}+\beta_{U M D} \cdot R_{U M D, t}^{e}+\varepsilon_{t}$, where $R_{T M I, t}^{e}$ is the return in month $t$ of the top-minus-index portfolio of a particular strategy, $R_{M, t}^{e}$ the excess return of the equally-weighted equity markets portfolio in US dollars minus the 1-month US T-bill return in month $t . R_{S M B, t}^{e}$ (small-minus-big), $R_{H M L, t}^{e}$ (high-minus-low), and $R_{U M D, t}^{e}$ (up-minus-down) are Top minus Bottom returns on respectively size, book-to-market, and 6-month momentum factor portfolios. All portfolios are formed as described in Table 2. Country neutrality is only applied to the size portfolio. $\mathrm{t}($.) is the $\mathrm{t}$-value for the regression coefficients and are corrected for heteroskedasticity and autocorrelation using Newey and West (1987). Panel A takes as the set of base assets the four portfolios based on global developed equity markets and Panel B contains results based on base assets from global emerging equity markets.

\begin{tabular}{lcccccccrrrrr} 
& TMI & $t(T M I)$ & $\alpha$ & $t(\alpha)$ & \multicolumn{1}{c}{$\beta_{M}$} & \multicolumn{1}{c}{$t\left(\beta_{M}\right)$} & $\beta_{\text {HML }}$ & $t\left(\beta_{\text {HML }}\right)$ & $\beta_{\text {SMB }}$ & $t\left(\beta_{\text {SMB }}\right)$ & $\beta_{\text {UMD }}$ & $t\left(\beta_{\text {UMD }}\right)$ \\
\hline \hline Panel A: Global developed markets & & & & & & & & & \\
\hline B/M & 0.74 & 3.05 & 0.70 & 2.87 & -0.04 & -0.73 & -0.02 & -0.15 & 0.24 & 1.84 & 0.02 & 0.25 \\
E/P & 1.26 & 5.55 & 1.23 & 5.69 & 0.05 & 1.23 & -0.10 & -1.48 & 0.17 & 1.51 & 0.04 & 0.61 \\
D/P & 0.41 & 1.72 & 0.56 & 2.54 & -0.09 & -2.17 & -0.06 & -0.88 & -0.17 & -1.88 & -0.11 & -2.26 \\
\hline MOM3 & 0.95 & 6.52 & 0.88 & 6.18 & -0.01 & -0.15 & -0.01 & -0.36 & 0.11 & 1.44 & 0.09 & 2.63 \\
MOM6 & 0.77 & 4.02 & 0.75 & 4.26 & 0.01 & 0.21 & -0.05 & -0.82 & 0.11 & 1.31 & 0.03 & 0.59 \\
MOM12 & 0.59 & 3.08 & 0.57 & 2.80 & 0.04 & 0.73 & 0.05 & 0.87 & -0.04 & -0.44 & -0.01 & -0.20 \\
\hline Size & 0.47 & 2.58 & 0.52 & 3.03 & -0.05 & -1.18 & 0.05 & 0.96 & -0.06 & -0.74 & -0.09 & -1.96 \\
\hline \hline
\end{tabular}

\begin{tabular}{|c|c|c|c|c|c|c|c|c|c|c|c|c|}
\hline \multicolumn{13}{|c|}{ Panel B: Global emerging markets } \\
\hline $\mathrm{B} / \mathrm{M}$ & 0.74 & 3.05 & 0.73 & 2.73 & -0.01 & -0.27 & 0.02 & 0.33 & 0.08 & 0.83 & -0.03 & -0.54 \\
\hline$E / P$ & 1.26 & 5.55 & 1.26 & 5.28 & 0.04 & 1.46 & -0.03 & -0.82 & 0.11 & 1.52 & 0.00 & 0.00 \\
\hline$D / P$ & 0.41 & 1.72 & 0.46 & 2.06 & -0.07 & -2.78 & 0.02 & 0.54 & -0.11 & -1.79 & -0.02 & -0.59 \\
\hline MOM3 & 0.95 & 6.52 & 0.92 & 6.00 & -0.02 & -0.75 & 0.02 & 0.67 & 0.02 & 0.44 & 0.02 & 0.68 \\
\hline MOM6 & 0.77 & 4.02 & 0.76 & 3.73 & 0.00 & -0.11 & 0.01 & 0.29 & 0.00 & -0.01 & 0.01 & 0.35 \\
\hline MOM12 & 0.59 & 3.08 & 0.61 & 3.18 & 0.02 & 0.48 & 0.00 & -0.04 & -0.09 & -1.22 & -0.01 & -0.20 \\
\hline$\overline{\text { Size }}$ & 0.47 & 2.58 & 0.50 & 2.93 & 0.00 & 0.06 & -0.03 & -0.77 & 0.09 & 1.22 & $\begin{array}{l}-0.03 \\
\end{array}$ & -1.02 \\
\hline
\end{tabular}




\section{Table 7: Downside Risk}

The first four rows display average, volatility, skewness and excess kurtosis of the monthly top-minus-index excess returns of frontier markets portfolios. The following rows compare the parametric percentile derived from the normal distribution to empirical estimates of tail risk calculated as $1 \%, 2.5 \%, 97.5 \%$ and $99 \%$ percentiles of the monthly excess returns. All portfolios are formed as described in Table 2. Country neutrality is only applied to the size portfolio.

\begin{tabular}{lccccccc}
\hline & $\mathrm{B} / \mathrm{M}$ & $\mathrm{E} / \mathrm{P}$ & $\mathrm{D} / \mathrm{P}$ & $\mathrm{MOM}$ & $\mathrm{MOM}$ & $\mathrm{MOM} 12$ & Size \\
\hline Average & $0.74 \%$ & $1.26 \%$ & $0.41 \%$ & $0.95 \%$ & $0.77 \%$ & $0.59 \%$ & $0.47 \%$ \\
Volatility & $2.92 \%$ & $2.35 \%$ & $2.36 \%$ & $1.59 \%$ & $2.15 \%$ & $2.26 \%$ & $2.08 \%$ \\
\hline Skewness & 0.80 & 0.54 & -0.07 & 0.61 & -2.03 & 1.23 & 0.25 \\
Kurtosis & 2.52 & 0.44 & 1.98 & 0.68 & 15.58 & 6.85 & 0.72 \\
\hline Theoretical 1\% & $-6.05 \%$ & $-4.22 \%$ & $-5.09 \%$ & $-2.75 \%$ & $-4.22 \%$ & $-4.67 \%$ & $-4.38 \%$ \\
Empirical 1\% & $-6.12 \%$ & $-2.99 \%$ & $-5.13 \%$ & $-2.48 \%$ & $-2.92 \%$ & $-5.19 \%$ & $-4.19 \%$ \\
\hline Theoretical 2.5\% & $-4.98 \%$ & $-3.35 \%$ & $-4.22 \%$ & $-2.17 \%$ & $-3.44 \%$ & $-3.84 \%$ & $-3.61 \%$ \\
Empirical 2.5\% & $-4.68 \%$ & $-2.65 \%$ & $-3.46 \%$ & $-1.50 \%$ & $-2.30 \%$ & $-2.90 \%$ & $-3.60 \%$ \\
\hline Theoretical 97.5\% & $6.45 \%$ & $5.87 \%$ & $5.04 \%$ & $4.07 \%$ & $4.97 \%$ & $5.02 \%$ & $4.55 \%$ \\
Empirical 97.5\% & $7.00 \%$ & $6.51 \%$ & $4.80 \%$ & $4.79 \%$ & $4.75 \%$ & $4.82 \%$ & $4.73 \%$ \\
\hline Theoretical 99\% & $7.52 \%$ & $6.73 \%$ & $5.91 \%$ & $4.65 \%$ & $5.76 \%$ & $5.85 \%$ & $5.31 \%$ \\
Empirical 99\% & $10.12 \%$ & $7.23 \%$ & $5.62 \%$ & $5.23 \%$ & $5.71 \%$ & $6.44 \%$ & $6.27 \%$ \\
\hline
\end{tabular}


Table 8: Results for the crisis period December 2008 to December 2011

Panel A presents excess returns of portfolios sorted on value, momentum and size characteristics and is similar to Table 2, but now for the 37 months out-of-sample period. Panel B presents the correlation of frontier markets portfolios with developed and emerging markets and is similar to Table 5.

\section{Panel A: Excess returns of portfolios sorted on characteristics}

\begin{tabular}{|c|c|c|c|c|c|c|c|c|c|c|c|c|c|c|}
\hline & \multicolumn{2}{|c|}{$\mathrm{B} / \mathrm{M}$} & \multicolumn{2}{|c|}{$\mathrm{E} / \mathrm{P}$} & \multicolumn{2}{|c|}{$\mathrm{D} / \mathrm{P}$} & \multicolumn{2}{|c|}{ MOM3 } & \multicolumn{2}{|c|}{ MOM6 } & \multicolumn{2}{|c|}{ MOM12 } & \multicolumn{2}{|c|}{ Size } \\
\hline & Return & $t$-value & Return & $t$-value & Return & $t$-value & Return & $t$-value & Return & $t$-value & Return & $t$-value & Return & $t$-value \\
\hline Top-Minus-Index & 0.68 & 1.08 & 0.98 & 2.30 & 0.66 & 2.14 & -0.08 & -0.24 & -0.38 & -0.72 & -0.56 & -0.86 & 1.40 & 2.70 \\
\hline Top-Minus-Bottom & 1.52 & 1.24 & 1.88 & 2.31 & 1.66 & 4.30 & -0.49 & -0.55 & -1.12 & -0.85 & -1.20 & -0.75 & 2.64 & 2.94 \\
\hline Index-Minus-Bottom & -0.84 & -1.24 & -0.90 & -1.86 & -1.01 & -3.70 & 0.41 & 0.61 & 0.75 & 0.85 & 0.64 & 0.63 & -1.25 & -2.45 \\
\hline EW Market risk adjusted & 0.69 & 1.14 & 0.99 & 2.27 & 0.66 & 2.37 & -0.08 & -0.30 & -0.38 & -0.93 & -0.57 & -1.29 & 1.40 & 3.04 \\
\hline VW Market risk adjusted & 0.78 & 1.31 & 1.04 & 2.37 & 0.69 & 2.14 & -0.23 & -0.75 & -0.62 & -1.26 & -0.91 & -1.64 & 1.39 & 2.64 \\
\hline
\end{tabular}

Panel B: Correlation of frontier markets portfolios with developed and emerging markets

\begin{tabular}{|c|c|c|c|c|c|c|}
\hline & \multicolumn{3}{|c|}{ Full sample 1997-2008 } & \multicolumn{3}{|c|}{ Crisis period 2008-2011 } \\
\hline & FM, EM & FM, DM & EM, DM & FM, EM & FM, DM & EM, DM \\
\hline Market & 0.48 & 0.50 & 0.82 & 0.76 & 0.78 & 0.90 \\
\hline $\mathrm{B} / \mathrm{M}$ & 0.09 & 0.06 & 0.46 & 0.57 & 0.48 & 0.79 \\
\hline$E / P$ & 0.01 & -0.05 & 0.27 & 0.63 & 0.63 & 0.88 \\
\hline $\mathrm{D} / \mathrm{P}$ & 0.14 & -0.15 & 0.12 & 0.36 & -0.34 & -0.15 \\
\hline Average value & 0.08 & -0.05 & 0.28 & 0.52 & 0.26 & 0.51 \\
\hline MOM3 & 0.05 & 0.20 & 0.32 & 0.33 & 0.36 & 0.83 \\
\hline MOM6 & 0.03 & 0.08 & 0.26 & 0.67 & 0.64 & 0.88 \\
\hline MOM12 & 0.07 & 0.00 & 0.32 & 0.72 & 0.68 & 0.83 \\
\hline Average momentum & 0.05 & 0.09 & 0.30 & 0.57 & 0.56 & 0.85 \\
\hline Size & 0.13 & 0.08 & 0.20 & 0.43 & 0.43 & 0.77 \\
\hline
\end{tabular}


Figure 1: Data coverage of stock and firm characteristics

The bold black line represents the number of firms in the S\&P Frontier BMI. The other lines represent the data availability for the book-to-market ratio (B/M), the earningsto-price ratio (E/P), the dividend yield (D/P), and 1-month momentum (MOM1).

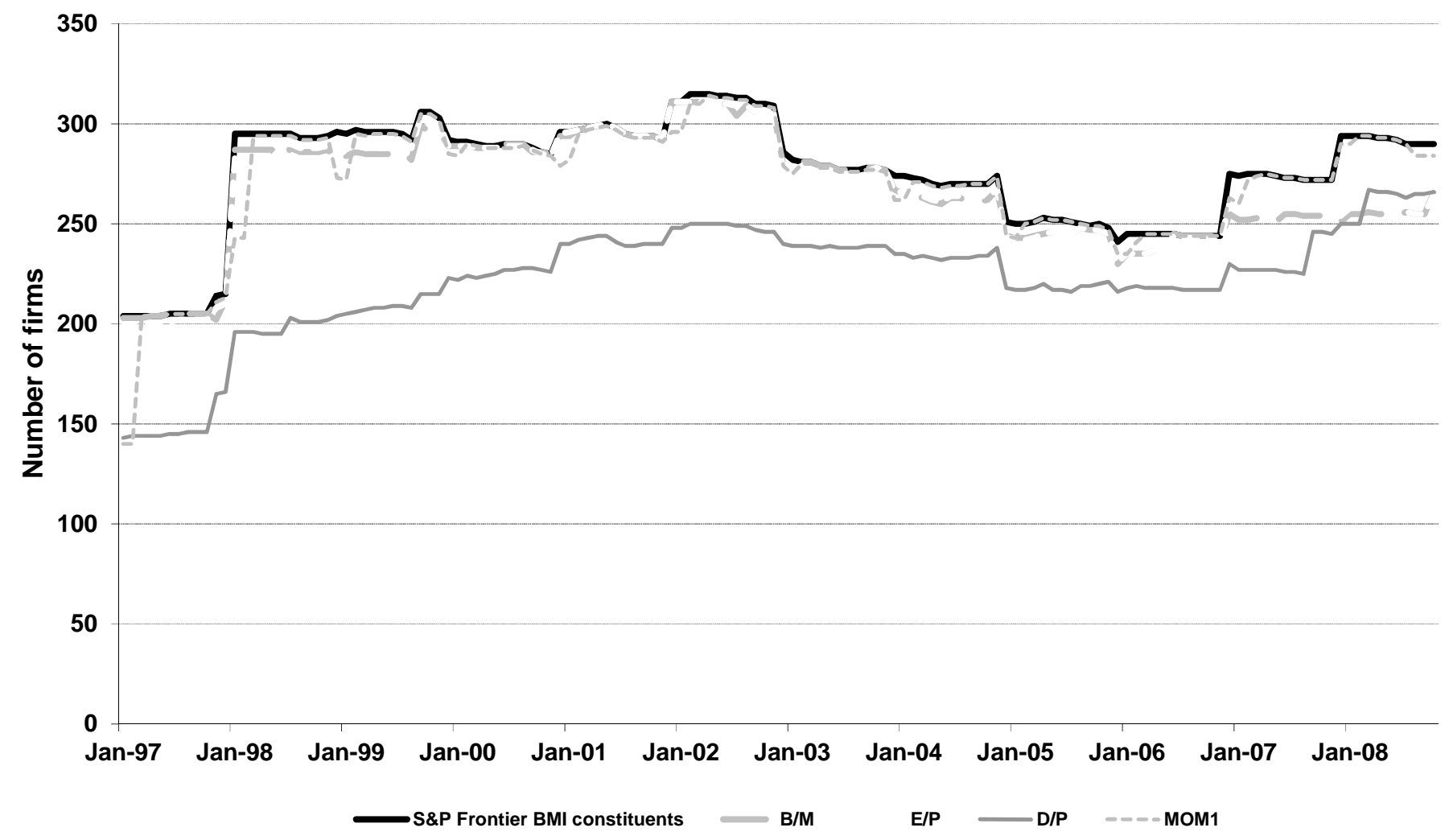


Figure 2: Mean-variance spanning tests for frontier markets value strategy.

This figure plots portfolios by their average excess return and volatility risk. The base assets are based on global developed markets and indicated with diamonds: RMRF is the market, SMB the size strategy, HML the value (book-to-market) strategy, and UMD the (6-month) momentum strategy. The dashed line with triangle is on the meanvariance frontier of the four developed markets portfolios. The solid line is the mean-variance frontier with in addition to the four base assets from the developed markets also the Top minus Index B/M value strategy based on frontier markets included (the stand alone frontier markets Top minus Index B/M value strategy is indicated with a square). The portfolio weights from each of these lines are also displayed in the figure, scaled such that the weights equal one.

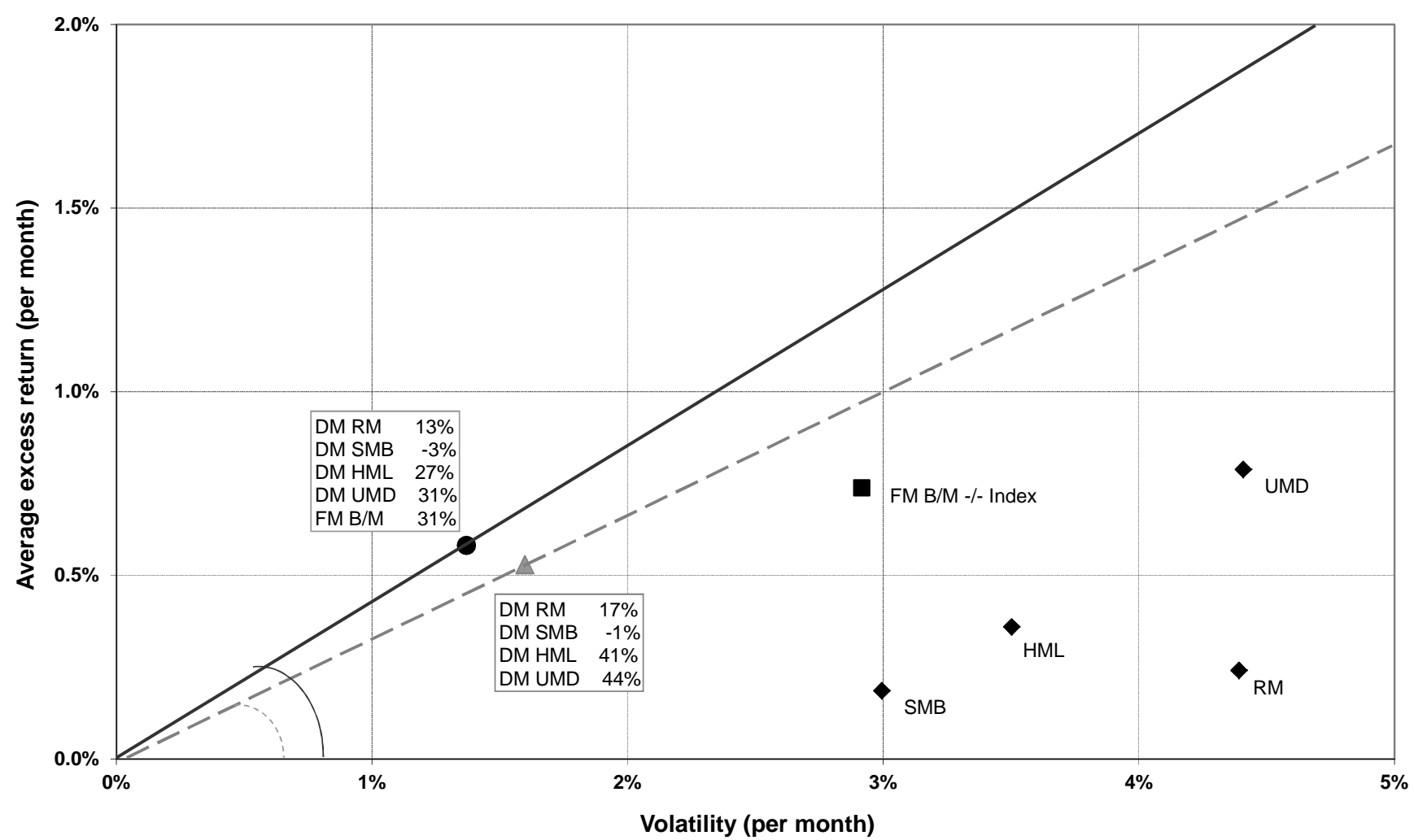




\section{Appendix A: Globalization scores for frontier market countries over time}

Panel A is based on the Index of Economic Freedom reported by The Heritage Foundation (HF), available at http://www.heritage.org. We report the average of the subindices Financial Freedom and Investment Freedom. Panel B is based on the KOF Index of Globalization constructed by the ETH Zurich (KOF), available at http://globalization.kof.ethz.ch. We report the Economic Globalization dimension scores. Panel C is based on the Economic Freedom of the World reported by Fraser Institute (EFW), available at http://www.freetheworld.com. The table reports the scores of the area Freedom to Trade Internationally. The column headers in the panels refer to the year the data have become available. We assume HF and KOF data have become available at the end of March every year, while EFW data have become available at the end of September every year. The last three rows show the average scores of frontier markets (FM), emerging markets (EM) based on stocks included in the S\&P/IFCI Emerging Markets index and developed markets (DM) based on stocks in the FTSE World index.

\begin{tabular}{|c|c|c|c|c|c|c|c|c|c|c|c|c|c|}
\hline Country & 1996 & 1997 & 1998 & 1999 & 2000 & 2001 & 2002 & 2003 & 2004 & 2005 & 2006 & 2007 & 2008 \\
\hline \multicolumn{14}{|l|}{ Panel A: HF scores } \\
\hline Bangladesh & 50 & 50 & 50 & 40 & 40 & 40 & 40 & 40 & 40 & 20 & 30 & 25 & 20 \\
\hline Botswana & 60 & 60 & 60 & 60 & 60 & 60 & 70 & 70 & 70 & 70 & 70 & 70 & 70 \\
\hline Bulgaria & 60 & 50 & 50 & 60 & 60 & 60 & 60 & 50 & 60 & 60 & 70 & 60 & 60 \\
\hline Côte d'Ivoire & 50 & 50 & 50 & 50 & 50 & 50 & 60 & 60 & 60 & 60 & 60 & 55 & 50 \\
\hline Croatia & & 50 & 50 & 50 & 50 & 50 & 50 & 50 & 60 & 60 & 60 & 55 & 55 \\
\hline Ecuador & 60 & 60 & 60 & 60 & 60 & 50 & 50 & 50 & 50 & 40 & 40 & 45 & 45 \\
\hline Estonia & & 80 & 80 & 80 & 80 & 80 & 90 & 90 & 90 & 90 & 90 & 90 & 85 \\
\hline Ghana & 50 & 50 & 50 & 50 & 50 & 50 & 50 & 50 & 50 & 40 & 50 & 50 & 50 \\
\hline Jamaica & 70 & 70 & 70 & 60 & 60 & 50 & 60 & 80 & 80 & 80 & 80 & 70 & 70 \\
\hline Kazakhstan & & & & & & & & & & & & 45 & 45 \\
\hline Kenya & 50 & 60 & 60 & 60 & 60 & 50 & 50 & 50 & 50 & 50 & 50 & 50 & 50 \\
\hline Latvia & & 70 & 70 & 70 & 70 & 70 & 70 & 70 & 70 & 70 & 70 & 70 & 70 \\
\hline Lebanon & & & & 60 & 60 & 60 & 60 & 60 & 60 & 50 & 50 & 50 & 50 \\
\hline Lithuania & 40 & 60 & 60 & 60 & 60 & 60 & 60 & 70 & 80 & 80 & 80 & 75 & 75 \\
\hline Mauritius & - & - & - & 60 & 60 & 60 & 60 & 60 & 60 & 60 & 60 & 65 & 65 \\
\hline Namibia & & & & 70 & 70 & 60 & 60 & 70 & 50 & 50 & 50 & 50 & 40 \\
\hline Panama & & & & & & & & & & & & 65 & 70 \\
\hline Romania & & 60 & 60 & 60 & 60 & 40 & 40 & 50 & 40 & 40 & 50 & 55 & 55 \\
\hline Slovakia & & & & & & & & & 80 & 80 & 80 & 75 & 75 \\
\hline Slovenia & 50 & 60 & 70 & 70 & 50 & 50 & 50 & 50 & 50 & 50 & 60 & 60 & 55 \\
\hline Trinidad and Tobago & 80 & 80 & 80 & 80 & 80 & 80 & 70 & 70 & 70 & 70 & 70 & 70 & 70 \\
\hline Tunisia & 70 & 70 & 70 & 60 & 60 & 60 & 60 & 50 & 50 & 30 & 30 & 30 & 30 \\
\hline Ukraine & & 40 & 40 & 40 & 40 & 40 & 40 & 40 & 40 & 40 & 40 & 40 & 40 \\
\hline Vietnam & & & & & & & & & & & 30 & 30 & 30 \\
\hline average FM score & 58 & 60 & 61 & 60 & 59 & 56 & 58 & 59 & 60 & 57 & 58 & 56 & 55 \\
\hline average EM score & 58 & 58 & 60 & 59 & 57 & 55 & 57 & 54 & 53 & 51 & 50 & 50 & 52 \\
\hline average DM score & 69 & 70 & 68 & 69 & 69 & 71 & 73 & 73 & 73 & 73 & 72 & 72 & 75 \\
\hline
\end{tabular}




\section{Appendix A: (continued)}

\begin{tabular}{|c|c|c|c|c|c|c|c|c|c|c|c|c|c|}
\hline Country & 1996 & 1997 & 1998 & 1999 & 2000 & 2001 & 2002 & 2003 & 2004 & 2005 & 2006 & 2007 & 2008 \\
\hline \multicolumn{14}{|l|}{ Panel B: KOF scores } \\
\hline Bangladesh & 11 & 11 & 11 & 15 & 16 & 18 & 21 & 24 & 25 & 26 & 28 & 32 & 33 \\
\hline Botswana & 52 & 54 & 59 & 61 & 64 & 64 & 64 & 67 & 73 & 76 & 74 & 72 & 65 \\
\hline Bulgaria & 43 & 46 & 47 & 53 & 59 & 58 & 61 & 66 & 65 & 62 & 67 & 74 & 72 \\
\hline Côte d'Ivoire & 31 & 34 & 34 & 34 & 36 & 39 & 41 & 45 & 44 & 45 & 45 & 45 & 48 \\
\hline Croatia & & 50 & 46 & 51 & 55 & 56 & 60 & 59 & 60 & 63 & 67 & 73 & 75 \\
\hline Ecuador & 41 & 44 & 51 & 52 & 52 & 54 & 59 & 61 & 59 & 57 & 56 & 55 & 54 \\
\hline Estonia & & 76 & 76 & 78 & 87 & 86 & 87 & 89 & 90 & 89 & 91 & 93 & 92 \\
\hline Ghana & 30 & 33 & 30 & 36 & 32 & 37 & 38 & 41 & 40 & 42 & 50 & 56 & 50 \\
\hline Jamaica & 66 & 68 & 69 & 68 & 67 & 68 & 70 & 71 & 70 & 70 & 69 & 73 & 73 \\
\hline Kazakhstan & & & & & & & & & & & & 72 & 73 \\
\hline Kenya & 40 & 38 & 37 & 32 & 33 & 32 & 32 & 33 & 32 & 34 & 39 & 37 & 37 \\
\hline Latvia & & 58 & 60 & 67 & 70 & 71 & 71 & 70 & 71 & 73 & 74 & 80 & 81 \\
\hline Lebanon & & & & - & - & - & - & - & - & - & - & - & - \\
\hline Lithuania & 54 & 55 & 57 & 63 & 67 & 70 & 69 & 69 & 73 & 75 & 73 & 78 & 79 \\
\hline Mauritius & 42 & 39 & 44 & 46 & 47 & 46 & 48 & 53 & 48 & 46 & 44 & 39 & 55 \\
\hline Namibia & & & & 56 & 55 & 56 & 50 & 55 & 54 & 60 & 57 & 59 & 59 \\
\hline Panama & & & & & & & & & & & & 79 & 78 \\
\hline Romania & & 34 & 36 & 41 & 46 & 50 & 51 & 54 & 54 & 54 & 56 & 65 & 69 \\
\hline Slovakia & & & & & & & & & 78 & 72 & 68 & 89 & 87 \\
\hline Slovenia & 52 & 52 & 52 & 56 & 59 & 59 & 59 & 63 & 66 & 69 & 73 & 79 & 79 \\
\hline Trinidad and Tobago & 66 & 69 & 73 & 73 & 73 & 73 & 71 & 72 & 76 & 74 & 74 & 72 & 75 \\
\hline Tunisia & 50 & 51 & 49 & 49 & 52 & 54 & 52 & 55 & 54 & 58 & 56 & 58 & 64 \\
\hline Ukraine & & 37 & 42 & 44 & 45 & 49 & 53 & 55 & 52 & 53 & 53 & 56 & 61 \\
\hline Vietnam & & & & & & & & & & & 47 & 50 & 53 \\
\hline average FM score & 44 & 47 & 49 & 51 & 53 & 55 & 56 & 58 & 59 & 60 & 60 & 65 & 66 \\
\hline average EM score & 54 & 54 & 57 & 58 & 59 & 60 & 60 & 61 & 64 & 66 & 66 & 67 & 66 \\
\hline average DM score & 72 & 74 & 74 & 75 & 77 & 80 & 81 & 84 & 81 & 80 & 80 & 79 & 79 \\
\hline
\end{tabular}




\section{Appendix A: (continued)}

\begin{tabular}{|c|c|c|c|c|c|c|c|c|c|c|c|c|c|}
\hline Country & 1996 & 1997 & 1998 & 1999 & 2000 & 2001 & 2002 & 2003 & 2004 & 2005 & 2006 & 2007 & 2008 \\
\hline \multicolumn{14}{|l|}{ Panel C: EFW scores } \\
\hline Bangladesh & 1.8 & 3.1 & 3.1 & 3.1 & 3.1 & 3.1 & 5.1 & 5.4 & 5.6 & 5.4 & 5.4 & 5.5 & 5.9 \\
\hline Botswana & 7.3 & 6.8 & 6.8 & 6.8 & 6.8 & 6.8 & 7.8 & 7.7 & 7.6 & 7.3 & 7.1 & 6.8 & 6.9 \\
\hline Bulgaria & 4.3 & 6.9 & 6.9 & 6.9 & 6.9 & 6.9 & 7.2 & 7.1 & 6.7 & 7.2 & 7.3 & 7.2 & 7.7 \\
\hline Côte d'Ivoire & 5.2 & 5.8 & 5.8 & 5.8 & 5.8 & 5.8 & 6.0 & 6.0 & 6.1 & 6.1 & 6.0 & 5.8 & 6.0 \\
\hline Croatia & & 6.0 & 6.0 & 6.0 & 6.0 & 6.0 & 6.2 & 6.5 & 6.4 & 6.6 & 6.7 & 6.5 & 6.7 \\
\hline Ecuador & 5.8 & 6.7 & 6.7 & 6.7 & 6.7 & 6.7 & 7.1 & 7.0 & 6.5 & 6.5 & 6.6 & 6.7 & 6.6 \\
\hline Estonia & & 8.6 & 8.6 & 8.6 & 8.6 & 8.6 & 8.8 & 8.8 & 8.5 & 8.4 & 8.4 & 8.1 & 8.1 \\
\hline Ghana & 5.0 & 5.8 & 5.8 & 5.8 & 5.8 & 5.8 & 7.2 & 7.3 & 6.9 & 7.2 & 7.1 & 5.6 & 7.0 \\
\hline Jamaica & 5.4 & 7.5 & 7.5 & 7.5 & 7.5 & 7.5 & 7.2 & 7.2 & 7.0 & 6.7 & 6.9 & 6.9 & 7.0 \\
\hline Kazakhstan & & & & & & & & & & & & 7.1 & 6.9 \\
\hline Kenya & 5.2 & 7.6 & 7.6 & 7.6 & 7.6 & 7.6 & 7.1 & 6.9 & 6.5 & 6.7 & 6.5 & 6.3 & 6.6 \\
\hline Latvia & & 8.0 & 8.0 & 8.0 & 8.0 & 8.0 & 7.2 & 7.6 & 7.4 & 7.5 & 7.4 & 7.4 & 7.4 \\
\hline Lebanon & & & & & - & & & - & - & & & - & \\
\hline Lithuania & - & 8.2 & 8.2 & 8.2 & 8.2 & 8.2 & 7.3 & 7.8 & 7.7 & 7.6 & 7.5 & 7.5 & 7.5 \\
\hline Mauritius & 5.6 & 7.2 & 7.2 & 7.2 & 7.2 & 7.2 & 6.8 & 7.0 & 6.5 & 6.3 & 6.1 & 7.2 & 7.4 \\
\hline Namibia & & & & 6.4 & 6.4 & 6.4 & 6.2 & 6.7 & 6.5 & 6.5 & 6.4 & 6.3 & 6.4 \\
\hline Panama & & & & & & & & & & & & 7.9 & 8.3 \\
\hline Romania & & 5.9 & 5.9 & 5.9 & 5.9 & 5.9 & 6.4 & 6.5 & 6.6 & 6.7 & 6.9 & 7.1 & 7.1 \\
\hline Slovakia & & & & & & & & & 8.2 & 8.3 & 8.8 & 8.1 & 8.2 \\
\hline Slovenia & - & 7.1 & 7.1 & 7.1 & 7.1 & 7.1 & 7.1 & 7.2 & 7.0 & 7.2 & 7.4 & 7.2 & 7.2 \\
\hline Trinidad and Tobago & 3.9 & 7.3 & 7.3 & 7.3 & 7.3 & 7.3 & 6.7 & 7.2 & 6.9 & 6.9 & 7.1 & 6.9 & 7.1 \\
\hline Tunisia & 6.0 & 6.2 & 6.2 & 6.2 & 6.2 & 6.2 & 6.0 & 6.4 & 6.0 & 6.0 & 6.2 & 6.0 & 6.2 \\
\hline Ukraine & & 6.2 & 6.2 & 6.2 & 6.2 & 6.2 & 7.0 & 6.8 & 7.1 & 6.9 & 7.0 & 6.5 & 6.4 \\
\hline Vietnam & & & & & & & & & & 6.8 & 6.7 & 6.6 & 6.9 \\
\hline average FM score & 5.0 & 6.7 & 6.7 & 6.7 & 6.7 & 6.7 & 6.9 & 7.0 & 6.9 & 6.9 & 6.9 & 6.8 & 7.0 \\
\hline average EM score & 5.9 & 5.9 & 5.8 & 5.8 & 5.8 & 5.8 & 6.7 & 7.1 & 7.2 & 7.1 & 7.1 & 7.2 & 7.1 \\
\hline average DM score & 7.7 & 7.7 & 7.7 & 7.6 & 7.6 & 7.6 & 7.9 & 8.3 & 8.2 & 7.9 & 7.9 & 7.8 & 7.4 \\
\hline
\end{tabular}




\section{Appendix B: Individualism scores for frontier countries}

Data on individualism obtained from www.geert-hofstede.com. The scores are displayed for the frontier countries for which the data is available. The group with lowindividualism scores are all countries, except for Estonia, Jamaica, Lebanon, and Slovakia (in black), who have a score above the threshold of 32 that is the cut-off point of the bottom individualism group in Chui, Titman, and Wei (2010).

\begin{tabular}{lclc}
\hline \multicolumn{1}{c}{ Country } & Score & Country & Score \\
\hline Bangladesh & 20 & Lebanon & 38 \\
Botswana & - & Lithuania & - \\
Bulgaria & 30 & Mauritius & - \\
Croatia & - & Namibia & - \\
Ecuador & 8 & Panama & 11 \\
Estonia & 60 & Romania & 30 \\
Ghana & 20 & Slovakia & 52 \\
IvoryCoast & - & Slovenia & - \\
Jamaica & 39 & Trinidad \& Tobago & 16 \\
Kazakhstan & - & Tunisia & - \\
Kenya & 27 & Ukraine & - \\
Latvia & - & Vietnam & 20 \\
\hline Average frontier markets below treshhold 32 & 20 \\
Average bottom individualism Chui et al (2010) & 22 \\
World average as reported by Hofstede (2001) & 43 \\
\hline
\end{tabular}




\section{Appendix C: Regressions of frontier markets excess returns on US risk factors}

Panel A of the table presents coefficient estimates and t-values of the regression equation: $R_{T M I, t}^{e}=\alpha+\beta_{M} \cdot R_{M, t}^{e}+\beta_{S M B} \cdot R_{S M B, t}^{e}+\beta_{H M L} \cdot R_{H M L, t}^{e}+\beta_{U M D} \cdot R_{U M D, t}^{e}+\varepsilon_{t}$, where $R_{T M I, t}^{e}$ is the return in month $t$ of the top-minus-index portfolio of a particular strategy, $R_{M, t}^{e}$ the excess return of the equally-weighted equity markets portfolio in US dollars minus the 1-month US T-bill return in month $t . R_{S M B, t}^{e}$ (small-minus-big), $R_{H M L, t}^{e}$ (high-minus-low), and $R_{U M D, t}^{e}$ (up-minus-down) are returns on respectively size, book-to-market, and momentum factor portfolios. All portfolios are formed as described in Table 2. Country neutrality is only applied to the size portfolio. Data on the USbased portfolios are from the online data library of Kenneth French. $\mathrm{t}($.$) is the \mathrm{t}$-value for the regression coefficients and are corrected for heteroskedasticity and autocorrelation using Newey and West (1987). In Panel B we add as a fifth factor the traded liquidity factor (LIQ PS), obtained from the website of Luboš Pástor. Details on the liquidity factor can be found in Pastor and Stambaugh (2003). In Panel C, we add the non-traded fixed-transitory (LIQ S-FT) and variable-permanent (LIQ S-VP) liquidity factors, obtained from Ronnie Sadka and described in more detail in Sadka (2006).

\begin{tabular}{|c|c|c|c|c|c|c|c|c|c|c|c|c|c|c|c|c|c|c|}
\hline & TMI & $t(T M I)$ & $\alpha$ & $t(\alpha)$ & $\beta_{M}$ & $t\left(\beta_{M}\right)$ & $\beta_{S M B}$ & $t\left(\beta_{S M B}\right)$ & $\beta_{H M L}$ & $t\left(\beta_{\text {HML }}\right)$ & $\beta$ UMD & $t(\beta \cup M D)$ & $\beta_{L I Q P S}$ & $t\left(\beta_{\perp I Q P S}\right)$ & $\beta_{L I Q \text { S-FT }}$ & $t\left(\beta_{L I Q \text { S-F }}\right)$ & $\beta_{L I Q S-V P}$ & $t\left(\beta_{\perp \perp Q \text { S-VP }}\right)$ \\
\hline \multicolumn{19}{|c|}{ 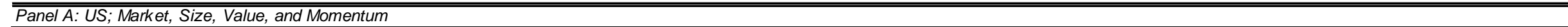 } \\
\hline $\mathrm{B} / \mathrm{M}$ & 0.74 & 3.05 & 0.72 & 2.93 & -0.06 & -1.11 & 0.09 & 1.24 & 0.11 & 1.40 & -0.05 & -1.21 & & & & & & \\
\hline$E / P$ & 1.26 & 5.55 & 1.28 & 5.84 & 0.02 & 0.35 & 0.00 & 0.08 & 0.07 & 1.36 & -0.04 & -1.56 & & & & & & \\
\hline $\mathrm{D} / \mathrm{P}$ & 0.41 & 1.72 & 0.47 & 2.12 & -0.06 & -1.56 & -0.11 & -1.94 & -0.03 & -0.78 & 0.00 & -0.14 & & & & & & \\
\hline MOM3 & 0.95 & 6.52 & 0.93 & 6.46 & -0.02 & -0.45 & 0.01 & 0.11 & 0.04 & 1.05 & 0.02 & 0.67 & & & & & & \\
\hline MOM6 & 0.77 & 4.02 & 0.78 & 4.24 & 0.00 & -0.08 & -0.05 & -0.94 & 0.03 & 0.70 & 0.00 & -0.03 & & & & & & \\
\hline MOM12 & 0.59 & 3.08 & 0.62 & 3.11 & 0.00 & 0.04 & -0.05 & -0.90 & -0.01 & -0.23 & -0.01 & -0.17 & & & & & & \\
\hline Size & 0.47 & 2.58 & 0.59 & 3.57 & -0.05 & -1.38 & -0.04 & -0.71 & -0.04 & -0.76 & -0.10 & -4.38 & & & & & & \\
\hline \multicolumn{19}{|c|}{ Panel B: US; Market, Size, Value, Momentum, and Liquidity (PS) } \\
\hline $\mathrm{B} / \mathrm{M}$ & 0.74 & 3.05 & 0.68 & 2.72 & -0.08 & -1.15 & 0.08 & 1.01 & 0.11 & 1.36 & -0.05 & -1.28 & 0.05 & 0.55 & & & & \\
\hline$E / P$ & 1.26 & 5.55 & 1.26 & 5.51 & 0.00 & 0.08 & -0.01 & -0.09 & 0.07 & 1.33 & -0.05 & -1.60 & 0.03 & 0.47 & & & & \\
\hline $\mathrm{D} / \mathrm{P}$ & 0.41 & 1.72 & 0.49 & 2.05 & -0.05 & -1.09 & -0.10 & -1.57 & -0.02 & -0.71 & 0.00 & -0.13 & -0.02 & -0.30 & & & & \\
\hline$\overline{\mathrm{MOM} 3}$ & 0.95 & 6.52 & 0.93 & 5.92 & -0.02 & -0.44 & 0.01 & 0.12 & 0.04 & 1.05 & 0.02 & 0.67 & 0.00 & -0.05 & & & & \\
\hline MOM6 & 0.77 & 4.02 & 0.84 & 4.60 & 0.02 & 0.40 & -0.02 & -0.48 & 0.04 & 0.88 & 0.00 & 0.04 & -0.08 & -1.40 & & & & \\
\hline MOM12 & 0.59 & 3.08 & 0.66 & 3.28 & 0.02 & 0.45 & -0.03 & -0.52 & 0.00 & -0.09 & -0.01 & -0.16 & -0.06 & -1.09 & & & & \\
\hline Size & 0.47 & 2.58 & 0.63 & 3.61 & -0.04 & -0.73 & -0.03 & -0.39 & -0.03 & -0.60 & -0.10 & -4.38 & -0.05 & -0.73 & & & & \\
\hline \multicolumn{19}{|c|}{ 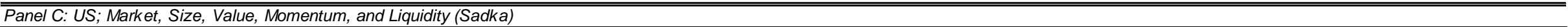 } \\
\hline $\mathrm{B} / \mathrm{M}$ & 0.74 & 3.05 & 0.73 & 2.96 & -0.08 & -1.26 & 0.04 & 0.50 & 0.09 & 1.16 & -0.06 & -1.57 & & & 0.03 & 2.32 & 0.00 & $\overline{0.79}$ \\
\hline$E / P$ & 1.26 & 5.55 & 1.31 & 6.36 & -0.02 & -0.43 & -0.06 & -1.19 & 0.06 & 1.05 & -0.07 & -2.50 & & & 0.02 & 1.06 & 0.01 & 3.02 \\
\hline $\mathrm{D} / \mathrm{P}$ & 0.41 & 1.72 & 0.46 & 2.02 & -0.04 & -1.16 & -0.09 & -1.29 & -0.02 & -0.60 & 0.01 & 0.21 & & & 0.00 & -0.23 & 0.00 & -1.05 \\
\hline MOM3 & 0.95 & 6.52 & 0.91 & 6.64 & -0.02 & -0.41 & 0.00 & -0.09 & 0.03 & 0.86 & 0.02 & 0.82 & & & 0.01 & 0.82 & 0.00 & -0.88 \\
\hline MOM6 & 0.77 & 4.02 & 0.77 & 4.13 & 0.01 & 0.12 & -0.04 & -0.82 & 0.03 & 0.69 & 0.01 & 0.32 & & & 0.00 & 0.55 & 0.00 & -0.89 \\
\hline MOM12 & 0.59 & 3.08 & 0.62 & 3.14 & 0.01 & 0.24 & -0.02 & -0.25 & 0.00 & 0.06 & 0.00 & 0.01 & & & -0.02 & -1.18 & 0.00 & -0.20 \\
\hline Size & 0.47 & 2.58 & 0.58 & 3.45 & -0.05 & -1.22 & -0.06 & -1.04 & -0.05 & -0.96 & -0.09 & -3.93 & & & 0.02 & 1.94 & 0.00 & -1.06 \\
\hline
\end{tabular}




\section{Appendix D: Regressions of frontier markets net excess returns on global risk factors}

The table presents coefficient estimates and t-values of the regression equation: $R_{T M I, t}^{e}=\alpha+\beta_{M} \cdot R_{M, t}^{e}+\beta_{S M B} \cdot R_{S M B, t}^{e}+\beta_{H M L} \cdot R_{H M L, t}^{e}+\beta_{U M D} \cdot R_{U M D, t}^{e}+\varepsilon_{t}$, where $R_{T M I, t}^{e}$ is the net portfolio return in excess of net index return in month $t$ of a particular strategy, $R_{M, t}^{e}$ the excess return of the equally-weighted equity markets portfolio in US dollars minus the 1-month US T-bill return in month $t . R_{S M B, t}^{e}$ (small-minus-big), $R_{H M L, t}^{e}$ (high-minus-low), and $R_{U M D, t}^{e}$ (up-minus-down) are returns on respectively size, book-to-market, and momentum factor portfolios. All portfolios are formed as described in Table 2. Country neutrality is only applied to the size portfolio. t(.) is the tvalue for the regression coefficients and are corrected for heteroskedasticity and autocorrelation using Newey and West (1987). Panel A takes as the set of base assets the four portfolios based on global developed equity markets and Panel B contains results based on base assets from global emerging equity markets.

\begin{tabular}{|c|c|c|c|c|c|c|c|c|c|c|c|c|}
\hline & TMI & $t(T M I)$ & $\alpha$ & $t(\alpha)$ & $\beta_{M}$ & $t\left(\beta_{M}\right)$ & $\beta_{H M L}$ & $t\left(\beta_{H M L}\right)$ & $\beta_{S M B}$ & $t\left(\beta_{S M B}\right)$ & $\beta_{U M D}$ & $t\left(\beta_{\cup M D}\right)$ \\
\hline \multicolumn{13}{|c|}{ Panel A: Global developed markets } \\
\hline $\mathrm{B} / \mathrm{M}$ & 0.56 & 2.77 & 0.49 & 2.37 & 0.02 & 0.42 & -0.08 & -0.91 & 0.25 & 2.04 & 0.08 & 1.25 \\
\hline$E / P$ & 0.64 & 2.73 & 0.57 & 2.39 & 0.06 & 1.15 & -0.10 & -1.27 & 0.17 & 1.42 & 0.11 & 1.57 \\
\hline $\mathrm{D} / \mathrm{P}$ & 0.64 & 2.99 & 0.79 & 4.00 & -0.09 & -2.34 & -0.13 & -2.37 & -0.05 & -0.56 & -0.10 & -2.21 \\
\hline MOM3 & 0.60 & 3.99 & 0.54 & 3.93 & -0.02 & -0.64 & -0.07 & -1.44 & 0.16 & 2.23 & 0.10 & 2.76 \\
\hline MOM6 & 0.39 & 1.95 & 0.39 & 2.13 & -0.03 & -0.62 & -0.10 & -1.50 & 0.20 & 2.27 & 0.01 & 0.24 \\
\hline MON12 & 0.16 & 0.80 & 0.11 & 0.57 & 0.01 & 0.19 & 0.07 & 0.98 & 0.01 & 0.05 & 0.02 & 0.44 \\
\hline \multicolumn{13}{|c|}{ Panel B: Global emerging markets } \\
\hline $\mathrm{B} / \mathrm{M}$ & 0.56 & 2.77 & 0.59 & 2.77 & 0.01 & 0.18 & -0.02 & -0.44 & -0.01 & -0.15 & -0.02 & -0.55 \\
\hline$E / P$ & 0.64 & 2.73 & 0.56 & 2.17 & 0.00 & -0.12 & 0.07 & 1.68 & -0.08 & -1.05 & 0.02 & 0.56 \\
\hline $\mathrm{D} / \mathrm{P}$ & 0.64 & 2.99 & 0.69 & 3.45 & -0.08 & -3.14 & 0.02 & 0.66 & -0.09 & -1.37 & -0.04 & -1.53 \\
\hline MOM3 & 0.60 & 3.99 & 0.58 & 3.75 & -0.03 & -1.06 & 0.01 & 0.17 & 0.08 & 2.03 & 0.01 & 0.53 \\
\hline MOM6 & 0.39 & 1.95 & 0.43 & 2.18 & -0.02 & -0.53 & -0.04 & -1.17 & 0.09 & 1.61 & -0.02 & -1.15 \\
\hline MOM12 & 0.16 & 0.80 & 0.20 & 1.10 & 0.02 & 0.46 & -0.04 & -0.79 & 0.07 & 1.23 & -0.02 & -0.67 \\
\hline
\end{tabular}

